\title{
An integrated approach to monitoring the calibration stability of operational dual-polarization radars
}

\author{
Mattia Vaccarono ${ }^{1}$, Renzo Bechini ${ }^{1,2}$, Chandra V. Chandrasekar ${ }^{1}$, Roberto Cremonini $^{2}$, and Claudio Cassardo ${ }^{3}$ \\ ${ }^{1}$ Colorado State University, Fort Collins, Colorado, USA \\ ${ }^{2}$ Arpa Piemonte, via Pio VII 9, Turin, Italy \\ ${ }^{3}$ Università degli Studi di Torino, via Pietro Giuria 1, Turin, Italy
}

Correspondence to: Mattia Vaccarono (mvaccar@engr.colostate.edu)

Received: 3 February 2016 - Published in Atmos. Meas. Tech. Discuss.: 15 February 2016

Revised: 30 September 2016 - Accepted: 5 October 2016 - Published: 8 November 2016

\begin{abstract}
The stability of weather radar calibration is a mandatory aspect for quantitative applications, such as rainfall estimation, short-term weather prediction and initialization of numerical atmospheric and hydrological models. Over the years, calibration monitoring techniques based on external sources have been developed, specifically calibration using the Sun and calibration based on ground clutter returns. In this paper, these two techniques are integrated and complemented with a self-consistency procedure and an intercalibration technique. The aim of the integrated approach is to implement a robust method for online monitoring, able to detect significant changes in the radar calibration. The physical consistency of polarimetric radar observables is exploited using the self-consistency approach, based on the expected correspondence between dual-polarization power and phase measurements in rain. This technique allows a reference absolute value to be provided for the radar calibration, from which eventual deviations may be detected using the other procedures. In particular, the ground clutter calibration is implemented on both polarization channels (horizontal and vertical) for each radar scan, allowing the polarimetric variables to be monitored and hardware failures to promptly be recognized. The Sun calibration allows monitoring the calibration and sensitivity of the radar receiver, in addition to the antenna pointing accuracy. It is applied using observations collected during the standard operational scans but requires long integration times (several days) in order to accumulate a sufficient amount of useful data. Finally, an intercalibration technique is developed and performed to compare colocated measurements collected in rain by two radars in overlapping regions. The integrated approach is performed on the
\end{abstract}

C-band weather radar network in northwestern Italy, during July-October 2014. The set of methods considered appears suitable to establish an online tool to monitor the stability of the radar calibration with an accuracy of about $2 \mathrm{~dB}$. This is considered adequate to automatically detect any unexpected change in the radar system requiring further data analysis or on-site measurements.

\section{Introduction}

Weather radar data are used not only for precipitation monitoring but also for quantitative applications, such as rainfall estimation, short-term weather prediction and initialization of numerical atmospheric and hydrological models. Therefore, the data quality of radars must be continuously monitored, as for example recommended by the Network of European Meteorological Services (EUMETNET) OPERA (Operational Programme for the Exchange of weather RAdar Information) program (Météo France and Emilia Romagna, 2012; OPERA 3-WP1.4b, 2012). Specifically, the stability of the radar calibration is a mandatory aspect for performing reliable rainfall measurements. Over the years, many calibration techniques based on external sources have been developed, e.g., calibration with the Sun, and ones based on fixed and well-known targets, e.g., calibration with ground clutter echoes. The calibration using the solar interferences was first proposed by Whiton et al. (1976) and has been subsequently applied on operational radars for the monitoring of the radar receiver chain and antenna pointing (Holleman and Beekhuis, 2004; Huuskonen and Holleman, 
2007; Holleman et al., 2010a, b; Huuskonen et al., 2014; Gabella et al., 2014 and Altube et al., 2015). The ground clutter calibration allows the stability of the radar calibration to be monitored automatically, specifically the transmitting and receiving chain of both polarization channels, through statistical analysis of the echo power return from fixed targets (Silberstein et al., 2008 and Wolff et al., 2015).

For a radar network, the stability of the radar calibration can also be monitored considering the joint observations in rain medium collected by two or more radars (Vukovic et al., 2014 and Ribaud et al., 2015). This intercalibration ensures the consistency and stability of the precipitation measurements by comparing the radar reflectivity values of two or more radars in the same area.

In addition, a self-consistency procedure can be performed to evaluate the absolute radar calibration in the case of heavy rain. Gorgucci et al. (1992) and Scarchilli et al. (1996) proposed and developed a procedure based on the radar reflectivity at horizontal polarization $\left(Z_{\mathrm{H}}\right)$, differential reflectivity $\left(Z_{\mathrm{dr}}\right)$ and specific differential phase shift $\left(K_{\mathrm{dp}}\right)$, known as self-consistency since these three radar observables lie in a limited three-dimensional space for rain medium.

The radar calibration is also often monitored using observations collected by a rain gauge network. However, due to the high spatiotemporal variability of the $Z-R$ relations, this method is more indicated for the long-term bias assessment, and it has not been considered in this study.

In this paper we propose an integrated approach to monitoring the calibration stability of operational radars based on the abovementioned calibration techniques. The paper is organized as follows. Section 2 describes the radars and the data on which the proposed approach for the online calibration monitoring is performed. Section 3 reviews the selfconsistency procedure for the radar absolute calibration and the calibration monitoring techniques, namely intercalibration, ground clutter calibration and Sun calibration. The results of each calibration technique are discussed in Sect. 4. In Sect. 5, the integrated approach to monitoring the calibration stability of operational radars is discussed, and conclusions are drawn.

\section{Arpa Piemonte C-band weather radars}

The calibration monitoring of the Regional Agency for the Protection of the Environment (Arpa) of Piemonte C-band weather radars is evaluated for the period between 28 July and 13 October 2014 on the operational volume scans. The absolute calibration of the radars is checked using the selfconsistency procedure when precipitation occurs in the radar domain. During the whole period, the radar calibration is monitored using the ground clutter calibration, the Sun calibration and the intercalibration procedures.

The continuous surveillance of the territory in the northwestern region of Italy is operated by Arpa Piemonte, which

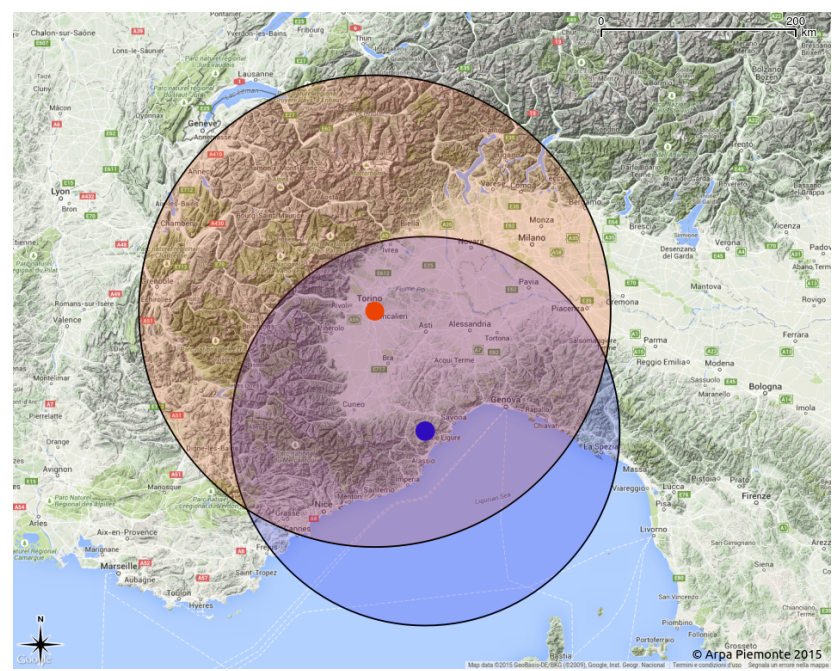

Figure 1. Weather radars in northwestern Italy. The circles correspond to the scan domains, and the colors are related to the markers on the map. The red and blue markers represent the two C-band radar locations. The circles represent the Bric della Croce scan (red) and the Monte Settepani scan (blue).

manages two C-band weather radars and a mobile X-band radar for research purposes. The two C-band radars are located at Bric della Croce hill and at Monte Settepani (Fig. 1). The Bric della Croce radar is located on the hills near Turin, at $736 \mathrm{~m}$ above sea level (a.s.l.). It is placed on the top of a $33 \mathrm{~m}$ high tower and covers the Piemonte region. The east side of the radar domain does not present obstacles that may block the radar beam, while on the western side of the radar domain the visibility is limited by the Alps and, on the southern side, by the Apennines. The radar of Bric della Croce performs a volume scan every $5 \mathrm{~min}$. However, due to different filter settings on the scans starting at minute 0 and 5, for the purpose of this study only the scan starting at minute 0 is considered. The scan is composed of 11 elevations between -0.1 and $28.5^{\circ}$. The volume scan is polarimetric, and the observed parameters are $Z_{\mathrm{H}}, Z_{\mathrm{dr}}$, correlation coefficient $\rho_{h v}$, differential phase shift $\Phi_{\text {dp }}$ and Doppler velocity $V$. Each measure is the result of the integration of about 50 pulses for each polarization. The range of the volume scan is $170 \mathrm{~km}$, and the range resolution is $340 \mathrm{~m}$. The angular resolution is $1^{\circ}$. The pulse time width is $0.5 \mu$ s (short pulse). The Bric della Croce radar operates in dual-PRF (pulse repetition frequency) mode to mitigate the radar dilemma, with frequencies 882 and $588 \mathrm{~Hz}$.

The second C-band weather radar is located on top of Monte Settepani at 1386 m a.s.l., near Savona, in the Ligurian Apennines. This radar is managed by Arpa Piemonte in collaboration with the Liguria region. This strategic position allows the precipitation coming from the Mediterranean Sea to be monitored, which may cause severe hydrological effects. Furthermore, the Monte Settepani radar has excellent visi- 
bility in the north and east sectors, corresponding to the Po Valley and the mountain areas of Piemonte. The Monte Settepani radar performs a volume scan every $10 \mathrm{~min}$. The volume scan is polarimetric and the acquired parameters are the same as for the Bric della Croce radar. The volumetric scan is composed of seven elevations between -0.3 and $14.9^{\circ}$. The range is $136 \mathrm{~km}$, and the range resolution is $375 \mathrm{~m}$, using short pulses of $0.5 \mu \mathrm{s}$ and PRF of $1090 \mathrm{~Hz}$.

The specific differential phase shift $K_{\mathrm{dp}}$ is operationally calculated for both systems using the Wang and Chandrasekar (2009) algorithm. After $K_{\mathrm{dp}}$ estimation, a hydrometeor classification is performed on the dual-polarization observations (Bechini and Chandrasekar, 2015). The output of the classification is used to select the data for the different calibration procedures. In order to account for the effects of attenuation and differential attenuation, the rain profiling algorithm based on Testud et al. (2000) is applied to correct the horizontal reflectivity for path attenuation, while differential attenuation is linearly estimated from the horizontal attenuation (Bringi et al., 1990).

\section{Integrated approach for radar online calibration}

The calibration techniques are often investigated separately, and the task of each technique is the monitoring of a section of the radar system. The Sun calibration performs the monitoring of the radar receiving chain and the antenna pointing, using the Sun as a natural radio source. The ground clutter calibration is able to monitor the calibration stability of the radar transmitting chain together with the receiving chain. Nevertheless, in the case of loss of calibration in the radar transmitting chain the ground clutter calibration is unable to detect whether the loss of calibration affects the transmitting or receiving chain. By combining and comparing the Sun calibration together with the ground clutter calibration, it is possible to retrieve additional information about the eventual calibration change.

Moreover, to monitor the calibration stability of operational radars during precipitation, the intercalibration may be performed when a radar network is available. The intercalibration procedure allows the reflectivity measurements acquired by two radars over the same area to be compared.

The intercalibration, the Sun calibration and ground clutter calibration, however, only allow monitoring the eventual deviation of the radar calibration from a given reference value. Hence, it is required to verify the absolute calibration of the radar by the self-consistency procedure. The integrated approach involves the following procedures:

- intercalibration, performed whenever precipitation is detected in overlapping areas;

- self-consistency, performed in the rainfall events selected for the intercalibration;

- ground clutter calibration, performed daily;
- Sun calibration, performed over the previous 5 days.

Once a reference calibration value is established, e.g., based on the end-to-end self-consistency method, the two techniques (clutter and self-consistency) can be combined to provide a more comprehensive monitoring of the calibration stability:

$\Delta_{\mathrm{TR}}=\frac{\frac{1}{\sigma_{\text {Clut }}}\left(\mathrm{CLUT}-\mathrm{CLUT}_{\text {trend }}\right)+\frac{1}{\sigma_{\mathrm{SC}}}\left(\mathrm{BIAS}_{\mathrm{SC}}\right)}{\frac{1}{\sigma_{\text {Clut }}}+\frac{1}{\sigma_{\mathrm{SC}}}} \quad(\mathrm{dB})$,

where CLUT trend $_{\text {is }}$ the mean value of the clutter calibration outputs during the whole study period or, for real-time application, during the last 4 weeks, while CLUT and BIAS are weekly averaged. Each technique is weighted by the inverse of its uncertainty, named $\sigma$. The $\Delta_{\mathrm{TR}}$ uncertainty is estimated by propagating the uncertainties of the considered techniques.

\subsection{Self-consistency}

The polarimetric radar measurements of rainfall are selfconsistent (Scarchilli et al., 1996), since $Z_{\mathrm{H}}, Z_{\mathrm{dr}}$ and $K_{\mathrm{dp}}$ lie in a limited three-dimensional space for rain medium. For the triplet of measurements $Z_{\mathrm{H}}, Z_{\mathrm{dr}}$ and $K_{\mathrm{dp}}$, the selfconsistency technique allows obtaining estimates of one of the parameters based on the other two. This procedure combines two methods for the dual-polarization estimate of rainfall: one based on the reflectivity measurement at horizontal polarization and on the differential reflectivity, and one based on the specific differential propagation phase measurement. This latter estimator is assumed to be unbiased, since it is based on phase measurements, so it is immune to calibration issues (Gorgucci et al., 1992).

The distribution of drop sizes (DSD) and shapes are fundamental for deriving physically based rain rate algorithms. The raindrop size distribution describes the probability density (distribution function) of raindrops. A gamma distribution model (or a similar model such as lognormal distribution) can adequately describe many of the natural variations in the shape of raindrop size distributions (Ulbrich, 1983). For polarimetric radars, the three radar measurements $Z, Z_{\mathrm{dr}}$ and $K_{\mathrm{dp}}$ can be used in various combinations to estimate rain rate. These estimators are based on equilibrium shape model, such as the Beard-Chuang (Beard and Chuang, 1987), which describes the oblate shape of the rain drops. Among the radar rainfall algorithms discussed in the literature (Bringi and Chandrasekar, 2001), in this study we used the $R_{\mathrm{dr}}\left(Z, Z_{\mathrm{dr}}\right)$ and $R_{\mathrm{dp}}\left(K_{\mathrm{dp}}\right)$ algorithms.

A robust rain rate estimator can be constructed as

$R_{\mathrm{dr}}=c_{1} Z_{\mathrm{H}}^{a_{1}} 10^{0.1 b_{1} Z_{\mathrm{dr}}}$,

where $Z_{\mathrm{H}}$ is in linear units $\left(\mathrm{mm}^{6} \mathrm{~m}^{-3}\right)$ and $Z_{\mathrm{dr}}$ is in logarithmic scale (dB) (Gorgucci et al., 1992). Coefficients $a_{1}, b_{1}$ and $c_{1}$ at C-band $(5.45 \mathrm{GHz})$ are $0.91,-2.09$ and $5.8 \times 10^{-3}$, respectively (Bringi and Chandrasekar, 2001). 
Using the specific differential propagation phase and since $K_{\mathrm{dp}}$ is inversely proportional to wavelength in Rayleigh limit, a general $R\left(K_{\mathrm{dp}}\right)$ estimator can be written using a frequency-scaling argument in the form (Bringi and Chandrasekar, 2001)

$R_{\mathrm{dp}}=129\left(\frac{K_{\mathrm{dp}}}{f}\right)^{b_{2}}$,

where the unit of $R_{\mathrm{dp}}$ is millimeters per hour $\left(\mathrm{mm} \mathrm{h}^{-1}\right), K_{\mathrm{dp}}$ is in degrees per kilometer $\left({ }^{\circ} \mathrm{km}^{-1}\right)$ and $f$ is in gigahertz. At $5 \mathrm{GHz}$ frequency it reduces to

$R_{\mathrm{dp}}=32.8\left(K_{\mathrm{dp}}\right)^{0.85}$.

According to Gorgucci et al. (1992), the absolute calibration bias can be computed as a function of the slope of the scatterplot between $R_{\mathrm{dp}}$ and $R_{\mathrm{dr}}$. Let $\theta$ be the angle of the position vector formed by the coordinates of $R_{\mathrm{dp}}$ and $R_{\mathrm{dr}}$. It follows that $\tan (\theta)$ can be estimated as the slope of a linear model applied on the rain rate pairs. The system gain bias can be expressed on a decibel scale as

$B(\mathrm{~dB})=-\frac{10}{a_{1}} \log (\tan (\theta))$,

where $10 \log (\tan (\theta))$ is the slope of the linear regression computed on a decibel scale.

The application of the self-consistency technique requires that $Z_{\mathrm{dr}}$ be properly calibrated (Gorgucci et al., 2001). In order to verify the calibration of $Z_{\mathrm{dr}}$, we considered all measurements collected matching the following criteria:

- observations in liquid phase, as inferred from the application of the hydrometeor classification (Bechini and Chandrasekar, 2015);

- $\rho_{h v}>0.99$

- horizontal reflectivity between 10 and $20 \mathrm{dBZ}$. The lower limit is used to avoid noise-contaminated observations, while the higher limit correspond to drizzle or light rain conditions.

Using the abovementioned criteria results in selecting echoes from drizzle composed of nearly spherical droplets and expected differential reflectivity close to $0 \mathrm{~dB}$ or slightly positive.

The self-consistency technique is performed on liquidphase echoes, inferred from the hydrometeor classification; rain rates computed from negative values of $Z_{\mathrm{dr}}$ and $K_{\mathrm{dp}}$ are not considered in the analysis, since these values are unphysical in rain medium.

\subsection{Intercalibration}

The intercalibration ensures the consistency and stability of the precipitation measurements by comparing the radar reflectivity values of two or more radars operating in the same frequency band, over the same area and time. The areas are computed from the intersection of the radar beams with a theoretical model, considering the normal propagation of the radar beam. The operational intercalibration of the two C-band radars is performed when sufficient meteorological echoes (i.e., more than 100 pairs) are available in the overlapping area. This procedure is able to detect eventual calibration drifts. In order to compare measurements from different radars, the different viewing geometry should be carefully considered. The overlapping volumes are evaluated theoretically for each elevation of both considered radars. Ideally, the pair of radar cells $\left(\sim 1^{\circ} \times 0.3 \mathrm{~km}\right)$ should have similar size in order to obtain consistent results from the intercalibration. However, to increase the number of radar cells on which the intercalibration can be performed, some tolerances on the altitude of the main beam center and on the distance from the radars are set. The height from the ground (or sea level) of the radar beam is computed by

$h_{\text {beam }}=\sqrt{s_{\mathrm{r}}^{2}+\left(h_{0}+R_{\mathrm{E}}\right)^{2}+2 s_{\mathrm{r}}\left(h_{0}+R_{\mathrm{E}}\right) \sin \theta}-R_{\mathrm{E}}$,

where $s_{\mathrm{r}}$ is the slant range (i.e., the range along the beam), $h_{0}$ the radar height above the sea level and $R_{\mathrm{E}}$ the effective Earth radius. Considering the $3 \mathrm{~dB}$ beam width of the Bric della Croce and Monte Settepani antennas and the distance between the two radars, an example of vertical section of the two radar beam is displayed in Fig. 2a. The displayed elevations are $1.2^{\circ}$ (Bric della Croce) and $0.7^{\circ}$ (Monte Settepani), and the direction is SSE for Bric della Croce and NNW for Monte Settepani.

The vertical tolerance is set to $100 \mathrm{~m}$ above and below the intersection of the two main beam axes. To select radar cells with similar volume, a threshold is imposed on the difference of the distances between the selected cell and the two radars, i.e., $\left|\Delta_{\text {cell,RadarA }}-\Delta_{\text {cell,RadarB }}\right|$. When projected on the ground, this value must not exceed $40 \mathrm{~km}$. For each pair of elevations in the scan strategy of the two radars, intersecting bins in the overlapping area are computed. The beam height is calculated on a spatial grid with geographical coordinates, and the cells where the difference between the beam heights is below the tolerance are selected. The position of the detected cells is then converted from geographical coordinates to bin-azimuth coordinates of each radar.

The Bric della Croce radar is located at $736 \mathrm{~m}$ a.s.l. near Turin, while the Monte Settepani radar is at $1386 \mathrm{~m}$ a.s.l. in the Ligurian Apennines. One of the most suitable pairs of elevation scans is represented in Fig. $2 b$, where the beam height of the Bric della Croce scan at $1.2^{\circ}$ and the Monte Settepani scan at $0.7^{\circ}$ is shown. Due to the different radar altitudes, the second elevation scan of Monte Settepani is combined with the third elevation scan of the Bric della Croce radar, and the altitude of the main beam center axis is about $2500 \mathrm{~m}$. The overlapping volume that satisfies the vertical tolerance is displayed in blue and is located approximately above the Cuneo plain and Asti hills. Considering all elevation pairs, 

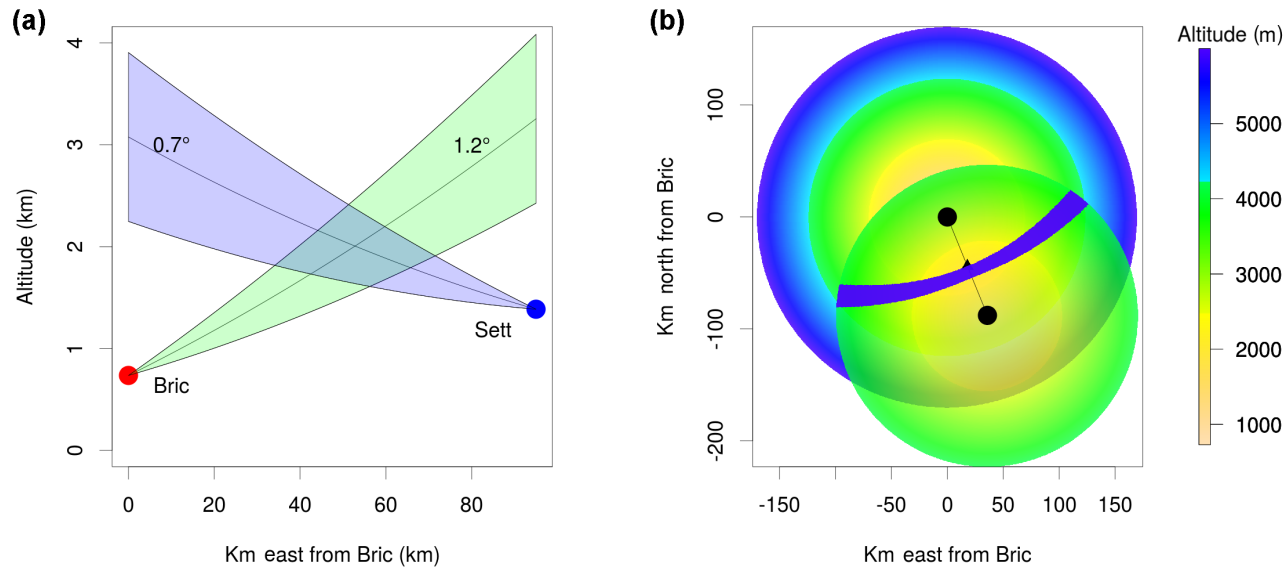

Figure 2. Intersection (a) of Bric della Croce (red point) and Monte Settepani (blue point) radar beams for elevations $0.7^{\circ}$ (Bric della Croce) and $1.2^{\circ}$ (Monte Settepani). The overlapping volume is about halfway between the two radars. Ground projection of the overlapping volume (b) of the Bric della Croce radar (elevation angle: $1.2^{\circ}$ ) and the Monte Settepani radar (elevation angle: $0.7^{\circ}$ ). The Bric della Croce radar is the northernmost. The colors represent the altitude in meters of the main beam center axis. The triangle is located halfway between the Bric della Croce and Monte Settepani radars.

the total number of intersecting bins that satisfy the imposed geometrical conditions is about $10^{5}$.

The intercalibration procedure then requires a statical look-up table (LUT) to store the polar coordinates of the intersecting bins. For these selected bins, the corresponding radar observations are extracted from the polar volumes, which have been preprocessed as reported in Sect. 2. In addition to the reflectivity, the correlation coefficient $\rho_{h v}$ is also considered in the analysis to select only rain measurements, associated with $\rho_{h v}>0.95$. Since different paths inside the melting layer may experience different attenuation, the data are selected below the freezing level retrieved from a numerical weather prediction (NWP) model, to reduce the uncertainty introduced by the melting layer. Furthermore, the radome may attenuate the electromagnetic radiation during heavy rain; therefore the reflectivity data measured during rain above any of the two radars are removed, using a threshold of $20 \mathrm{dBZ}$ on the mean value of the reflectivity measured close to the radar. Finally, to avoid considering observations in regions where the radar beam is blocked by the orography, a digital elevation model (DEM) is adopted to simulate the radar visibility along the radials.

\subsection{Ground clutter calibration}

The aim of the ground clutter calibration is to extract information about the radar system calibration from well-know targets. The ground clutter calibration uses a large set of echoes from scans of ground clutter at low elevation to provide a stable reference empirical cumulative distribution function (ECDF) of clutter reflectivity. The statistical approach is needed since clutter echoes may vary over time, e.g., due to anomalous propagation of the radar beam, wind, vegetation changes or snow coverage. The ground clutter cal- ibration allows monitoring the stability over time of the radar calibration considering the value where the ECDF reaches the 95th percentile (Silberstein et al., 2008). In this paper, this technique has been applied to both polarization channels of polarimetric weather radars.

The key points of the ground clutter calibration have been stated by Silberstein et al. (2008), and the success of the procedure depends on

- the ground returns' stability;

- the stability of elevation angle at which the clutter echoes are measured;

- the rainfall rate: the precipitation echoes must not dominate the clutter echoes.

When these conditions are met, surface clutter echoes can be used in the ground clutter calibration because of their limited variability over time. Different samples have a different ECDF, but the values at which the ECDF reaches 0.95 should not change over time for a given radar system (Silberstein et al., 2008).

The method of the ground clutter calibration is based on a clutter mask that is used to select clutter echoes that appear very frequently in the radar images. This is intended to minimize the possible contamination by meteorological echoes (Silberstein et al., 2008 and Wolff et al., 2015). The radar volumes are processed by the hydrometeor classification algorithm (Bechini and Chandrasekar, 2015) to identify clutter and meteorological echoes. Subsequently, empirical thresholds are applied to the volumes in order to be used for the clutter statistics: the percentage of meteorological echoes should be less than $1 \%$ and the percentage of clutter echoes greater than $12 \%$ of the total echoes inside the volume. The 

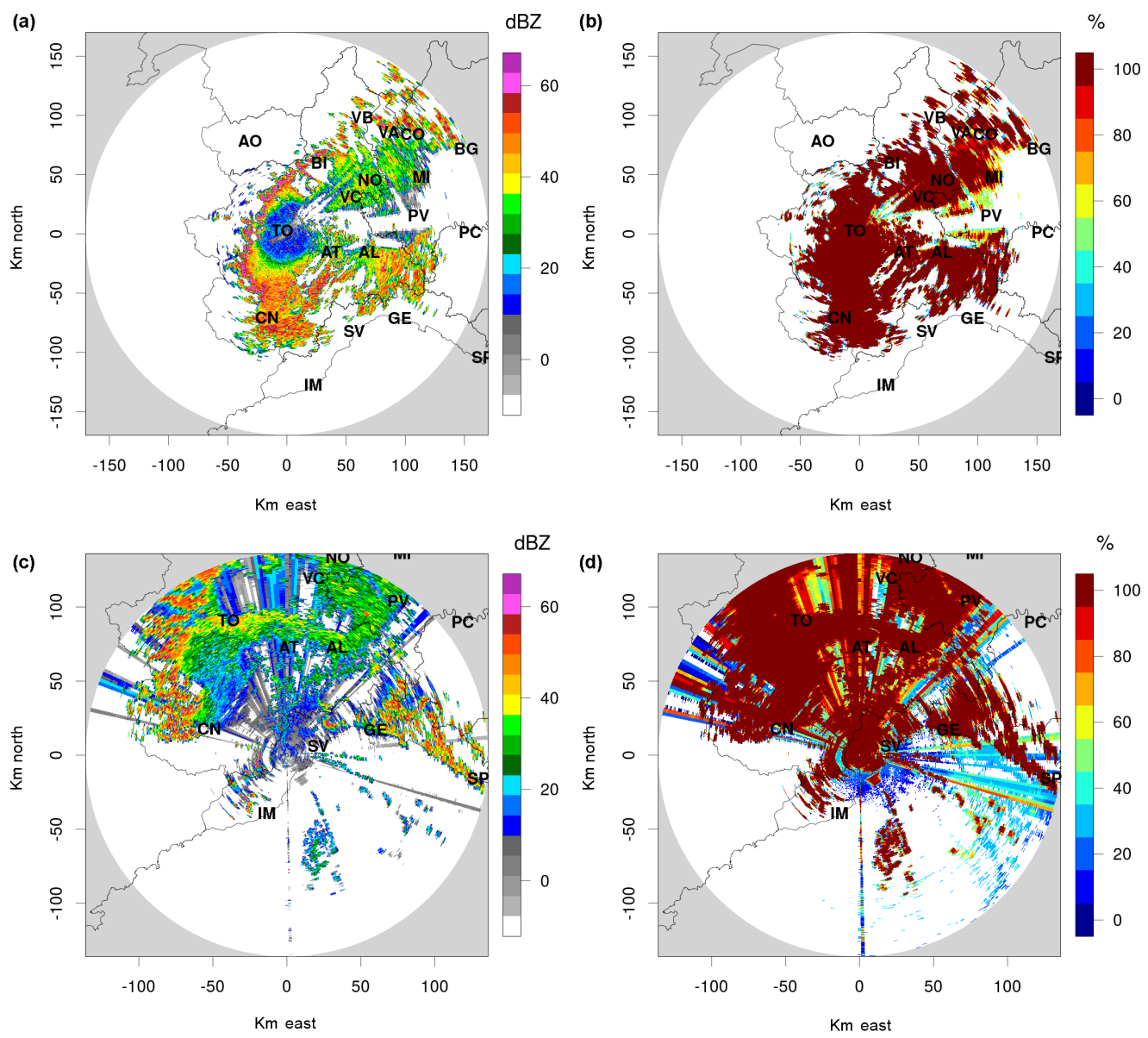

Figure 3. Mean reflectivity value and frequency of clutter echoes collected by the Bric della Croce (figures a and b) and by Monte Settepani (figures c and d) radars at the lowest elevations: -0.1 and $-0.3^{\circ}$, respectively. The maximum value exceeds $64 \mathrm{dBZ}$, and $100 \%$ represents very stable echoes.

radar volume scans meeting these criteria are processed on a daily basis to calculate a map of the average clutter reflectivity and a map of the frequency of occurrence of the clutter echoes. In order to avoid sudden clutter modifications, both maps are averaged with the corresponding maps from the previous days. The clutter masks are generated for each elevation of the volume scan and for each operational radar.

The clutter masks of the Bric della Croce radar at the lowest elevation are shown in Fig. 3a and b. Most of the clutter echoes have a mean frequency above $95 \%$ (Fig. 3b), meaning that there were no significant changes in their spatial distribution. The Alps are the most important source of clutter, whose reflectivity may exceed $65 \mathrm{dBZ}$ in some areas (Fig. 3a). The mean value and the frequency of clutter echoes for the Monte Settepani radar are shown in Fig. 3c and d.

It has been observed that the clutter echo ECDF may not have a steep slope around the 95th percentile, depending on the nature of the clutter echoes. Especially for the Monte Settepani radar, it has been noted that the limited slope of clutter echo ECDF yields a high uncertainty of the daily mean value of the 95th percentile. Therefore, we empirically investigated a threshold on the clutter reflectivity in order to increase the ECDF slope around the 95th percentile by removing weak clutter echoes. As a result, the threshold is imposed at $20 \mathrm{dBZ}$, corresponding to the best compromise between the ECDF slope and the amount of clutter echoes.

\subsection{Sun calibration}

The calibration of radar systems using the Sun as a radio source was first proposed by Whiton et al. (1976) and developed in several works by Tapping (2001a), Holleman and Beekhuis (2004), Huuskonen and Holleman (2007), Holleman et al. (2010a), Huuskonen et al. (2014), Gabella et al. (2014) and Altube et al. (2015). The Sun is used for monitoring the receiver calibration, the alignment of the radar antenna and checking the antenna gain (Rinehart, 2004). According to Huuskonen and Holleman (2007) and Holleman et al. (2010a), the antenna elevation and effective receiver system gain could be determined within $0.05^{\circ}$ and $0.2 \mathrm{~dB}$, 
respectively. The peculiarities of the Sun as a natural microwave source are

- $0.57^{\circ}$ apparent angular diameter;

- differential reflectivity about $0 \mathrm{~dB}$, because the radiation is not polarized;

- in radar polar plot (azimuth range), the solar interference appears as a uniform signal along one or more radials.

The Sun calibration is performed on reflectivity and differential reflectivity data. The method proposed by Holleman et al. (2010a) does not require stopping the operational radar scans (in contrast, the Sun tracking task requires stopping the normal radar operations) because it seeks the solar rays intercepted during the operational scanning. The Sun position is computed theoretically at the radar location, and then it is converted into azimuth and range bins. The automated routine scans the rays in the region (defined by an azimuthal tolerance) where the Sun should be seen by the radar. If the fraction of valid bins inside the detected ray is higher than typically 0.9 and the standard deviation of the computed power is less than $1 \mathrm{~dB}$, the ray is flagged as a solar ray (Holleman and Beekhuis, 2004).

The Sun elevation is corrected for the atmospheric refraction (Holleman et al., 2010a). The calculated correction is maximum at zero elevation and never exceeds $0.5^{\circ}$. The solar flux is continuously monitored at S-band by the Dominion Radio Astrophysical Observatory (DRAO) in Canada. The current solar flux is obtained from the ftp server of DRAO observatory: ftp://ftp.geolab.nrcan.gc.ca/data/solar_ flux/daily_flux_values/fluxtable.txt. The solar flux is given in solar flux units: $1 \mathrm{sfu}=10^{-22} \mathrm{~W} \mathrm{~m}^{-2} \mathrm{~Hz}^{-1}$. The S-band solar flux measurements can be applied to other frequencies with an accuracy of roughly $1 \mathrm{~dB}$. The reference solar flux is converted at the radar band (C-band) by Eq. (7) (Tapping, 2001b):

$F_{C}=0.71 \times\left(F_{S}-64\right)+126(\mathrm{sfu})$.

The estimated solar power $P_{\text {Sun }}$ received by the radar is given by

$P_{\text {Sun }}=\frac{1}{2} 10^{-13} \Delta f A F_{C}(\mathrm{~W})$,

where $\Delta f$ is the bandwidth of the radar receiver in megahertz and $A$ is the effective area of the antenna in square meters $\left(\mathrm{m}^{2}\right)$. The factor $1 / 2$ takes into account the unpolarized nature of the Sun, while the radar separately receives the horizontal and vertical polarized components of the incoming radiation. The estimated received solar power is compared with the solar power measured by the radar. The solar power is computed by the radar equation from the radar reflectivity measured at a given range:

$P(\mathrm{dBm})=Z(\mathrm{dBZ})-20 \log (R)-2 a R-C$,
Table 1. Summary of parameters used in the Sun calibration. The radar beam width refers to the C-band radars managed by Arpa Piemonte.

\begin{tabular}{lr}
\hline Parameter & Value \\
\hline One-way gaseous attenuation, $a\left(\mathrm{~dB} \mathrm{~km}^{-1}\right)$ & 0.019 \\
$4 / 3$ of Earth's radius, $R_{\mathrm{E}}(\mathrm{km})$ & 8495 \\
Solar beam width, $\Delta_{\mathrm{S}}\left(^{\circ}\right)$ & 0.57 \\
Radar beam width, $\Delta_{\mathrm{r}}\left({ }^{\circ}\right)$ & 0.94 \\
Antenna-Sun convolution, $\Delta_{\mathrm{c}}\left({ }^{\circ}\right)$ & 1 \\
Effective antenna-Sun convolution, $\Delta_{\mathrm{c}, \mathrm{eff}}\left({ }^{\circ}\right)$ & 1.2 \\
Azimuthal bin size, $\Delta x\left(^{\circ}\right)$ & 1 \\
\hline
\end{tabular}

where $R$ is the range $(\mathrm{km}), C$ the radar constant $(\mathrm{dB})$ and $a$ the one-way gaseous attenuation $(\mathrm{dB})$. The received solar power must be corrected for the gaseous attenuation between the radar antenna and the top of the atmosphere (TOA), for the imperfect overlap with the antenna sensitivity pattern and for the averaging of the received power while the antenna is rotating (Holleman and Beekhuis, 2004). The solar power received by the radar can be fit to a theoretical model in which the received power is represented by a Gaussian function. The model proposed by Holleman et al. (2010a) and discussed by Altube et al. $(2014,2015)$ is given by

$P_{\mathrm{det}}=A_{\mathrm{gas}} A_{\mathrm{avg}} P_{\mathrm{TOA}} e^{-4 \ln (2)\left[\frac{\left(\mathrm{az}^{-}-\mathrm{az}_{\mathrm{bias}}\right)^{2}}{\Delta_{\mathrm{c}, \mathrm{eff}}^{2}}+\frac{\left(\mathrm{el}-\mathrm{el}_{\mathrm{bias}}\right)^{2}}{\Delta_{\mathrm{c}}^{2}}\right]}$,

where $\Delta_{c}$ represents the vertical antenna-Sun convolution, and $\Delta_{\mathrm{c} \text {,eff }}$ the scanning solar width (Altube et al., 2015). The solar power received by the radar, named $P_{\mathrm{det}}$, and the power at the top of the atmosphere, named $P_{\mathrm{TOA}}$, are in milliwatts. The dimensionless gas attenuation and antenna averaging coefficients are $A_{\text {avg }}$ and $A_{\text {gas }}=10^{(a / 10)}$, respectively. The three model parameters are the power at the top of the atmosphere as seen by the radar $P_{\text {TOA }}$, the azimuthal bias az $z_{\text {bias }}$ and the elevation bias $\mathrm{el}_{\text {bias }}$. The biases represent the antenna pointing deviation and are computed from the difference $\Delta$ azimuth $=\mathrm{az}_{\mathrm{radar}}-\mathrm{az}_{\text {Sun }}$ and $\Delta$ elevation $=\mathrm{el}_{\mathrm{radar}}-\mathrm{el}_{\text {Sun }}$. The difference between the radar and Sun elevations is corrected by

$\Delta$ elevation $=\left(\mathrm{el}_{\text {radar }}-\mathrm{el}_{\text {Sun }}\right) \times \cos \left(\mathrm{el}_{\text {radar }}\right)$,

where $\cos \left(\mathrm{el}_{\mathrm{radar}}\right)$ projects the incline plane on the horizontal plane. Operatively, the fit is computed by the nonlinear leastsquares method, whose outputs are the fit parameters, their uncertainties and the fit residual standard error. The summary of parameters used in the Sun calibration is reported in Table 1 .

\section{Results}

The stability of the radar calibration is evaluated for the period between 28 July and 13 October 2014. The self- 


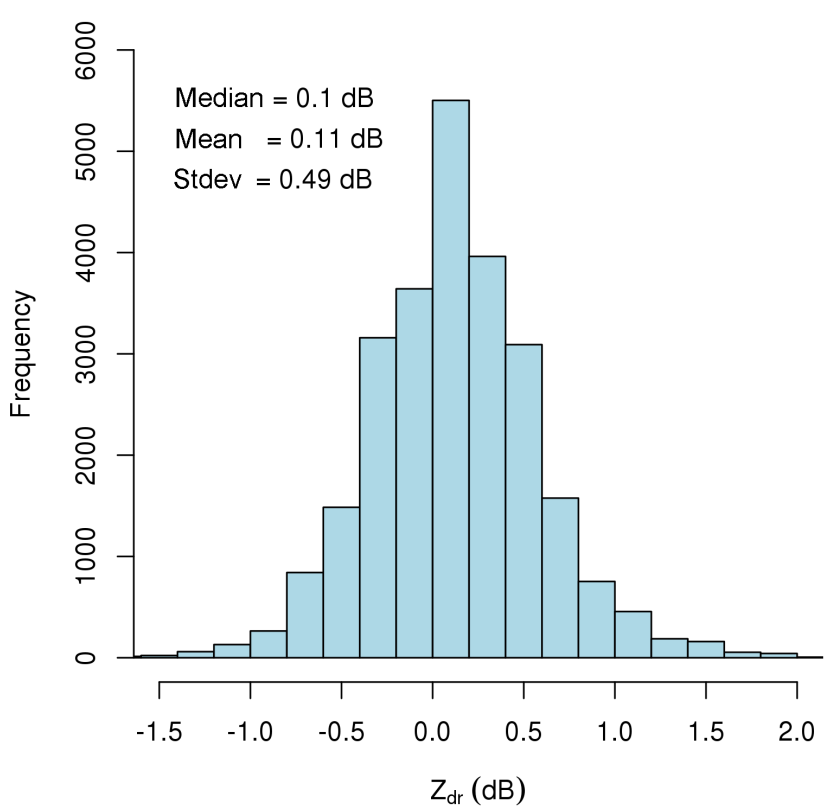

Figure 4. Histogram of differential reflectivity echoes satisfying the selection criteria discussed in Sect. 3.1. Bric della Croce radar, 13 October 2014.

consistency technique is adopted to ensure the absolute calibration of the radars during rainfall. In the analyzed period, when the precipitation data are not suitable to perform the self-consistency and the intercalibration procedures, the clutter and Sun calibration allow the stability of the calibration to be monitored.

\subsection{Radar absolute calibration with self-consistency}

The differential reflectivity calibration is verified, as reported in Sect. 3.1, using observations in drizzle. The results, reported in the histograms of Figs. 4 and 5, show a roughly symmetric distribution, with the most populated class being the one comprised between 0 and $0.2 \mathrm{~dB}$ for both systems. Therefore, $Z_{\mathrm{dr}}$ is considered to be properly calibrated, and the self-consistency technique may be performed. The rain rates previously described (Eqs. 2 and 4) are computed on the 10 min scans at $0.5^{\circ}$ for Bric della Croce and $0.7^{\circ}$ for Monte Settepani for the whole day. The rain rate estimation based on $Z_{\mathrm{H}}$ and $Z_{\mathrm{dr}}$ is compared to the $K_{\mathrm{dp}}$-based rain rate, which is considered unbiased. The results are presented as a density scatterplot of the rain rates in logarithmic scale, with the colors displaying the density of data. A linear fit with $1: 1$ slope is computed to estimate the intercept value, which is then converted to the system bias using Eq. (5). Since $K_{\mathrm{dp}}$ in light rain is noisy, inclusion of these data may affect the regression results. The standard deviation of estimated $K_{\mathrm{dp}}$ in drizzle $\left(\sigma_{\text {drizzle }}\left(K_{\mathrm{dp}}\right)\right)$, where $K_{\mathrm{dp}}$ is expected to be nearly $0^{\circ} \mathrm{km}^{-1}$, is assumed as the noise level. For both systems we found $\sigma_{\text {drizzle }}\left(K_{\mathrm{dp}}\right) \simeq 0.4^{\circ} \mathrm{km}^{-1}$. From Eq. (4), the corresponding

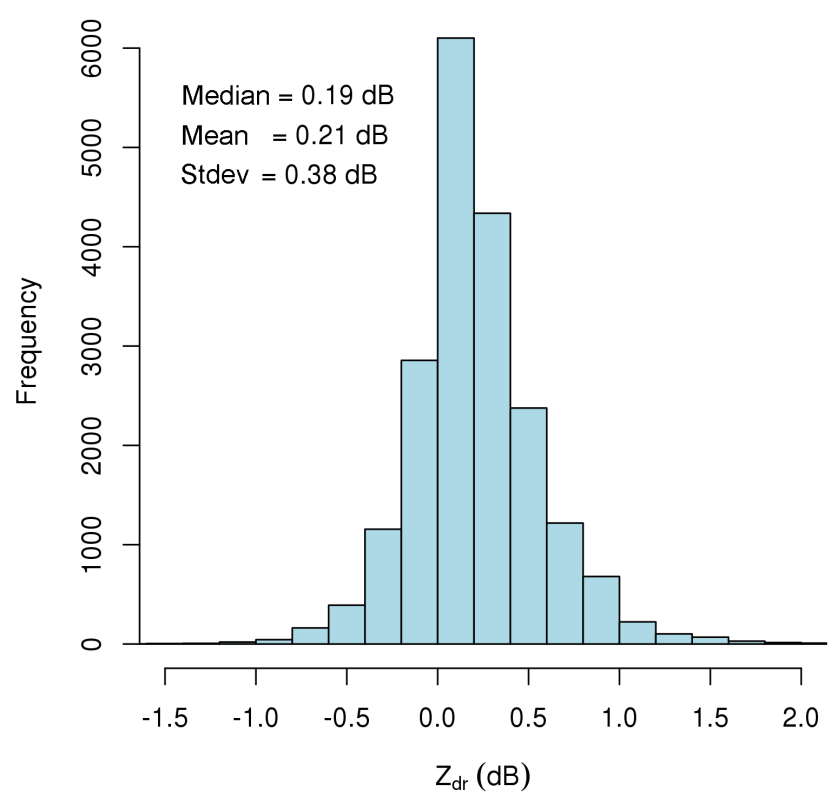

Figure 5. As in Fig. 4 but for the Monte Settepani radar, 10 October 2014.

rain rate value is

$R_{\min }=32.8\left(\sigma_{\text {drizzle }}\left(K_{\text {dp }}\right)\right)^{0.85} \simeq 14 \mathrm{~mm} \mathrm{~h}^{-1}$.

So, the minimum rain rate, considered for the estimation of the system gain bias, is $14 \mathrm{~mm} \mathrm{~h}^{-1}$, equivalent to $11 \mathrm{dBR}$ on a decibel scale for both radars. The perfect agreement of the two rain rate estimations is represented by the $1: 1$ line. In the density scatterplot, the total number of data, the bisector, the fit outputs (uncertainty, intercept and the correlation coefficient) and the computed bias are displayed. Thus, the selfconsistency technique is performed on 28 July 2014, when thunderstorm cells occurred in the Piemonte and Liguria regions. Figure 6 shows the density scatterplot of rain rates calculated on Bric della Croce data. For rain rates above $11 \mathrm{dBR}$, there is an overall fair agreement, with the highest density of data being below the $1: 1$ line. The computed system gain bias is slightly negative: $-0.9 \mathrm{~dB}$.

Figure 7 displays the density scatterplot of rain rates calculated on Monte Settepani data. For rain rates above $11 \mathrm{dBR}$, the higher amount of data is located above the $1: 1$ line, pointing out the overestimation of the $Z$ - and $Z_{\mathrm{dr}}$-based rain rate. The computed system gain bias is positive: $1 \mathrm{~dB}$.

The radar absolute calibration is also checked during the whole study period and, in particular, on 13 October 2014. During this event, a flood occurred in southeastern Piemonte (Arquata Scrivia), about $30 \mathrm{~km}$ north of Genoa, with $24 \mathrm{~h} \mathrm{cu}-$ mulative precipitation exceeding $400 \mathrm{~mm}$ (Fig. 8).

Figure 9 represents the rain rate density scatterplot in logarithmic scale for the Bric della Croce radar, showing a remarkable density pattern around the bisector. The computed system gain bias is $-0.49 \mathrm{~dB}$. For the Monte Settepani radar, 


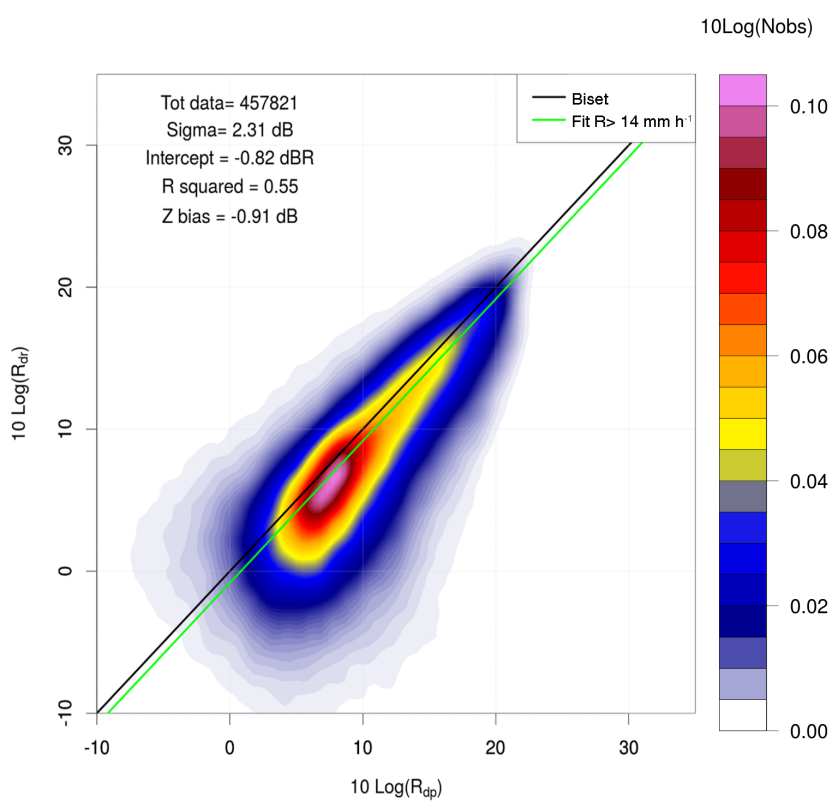

Figure 6. Self-consistency procedure applied on the Bric della Croce radar, 28 July 2014 . The $K_{\mathrm{dp}}$-based rain rate, on a decibel scale, is shown in the $x$ axis, and the rain rate based on $Z$ and $Z_{\mathrm{dr}}$, on a decibel scale, in the $y$ axis. The colors represent the density of data from blue (low density) to violet (high density), as reported in the color bar in logarithmic units using $1 \mathrm{dBR}$ intervals for both axes. The black and green line display the $1: 1$ line and the fit with slope set at 1 , respectively, performed on the data with rain rate greater than $14 \mathrm{~mm} \mathrm{~h}^{-1}$. The total number of data, the fit uncertainty, the intercept value (in $\mathrm{dB}$ ), the correlation coefficient and the computed system bias are reported in the plot.

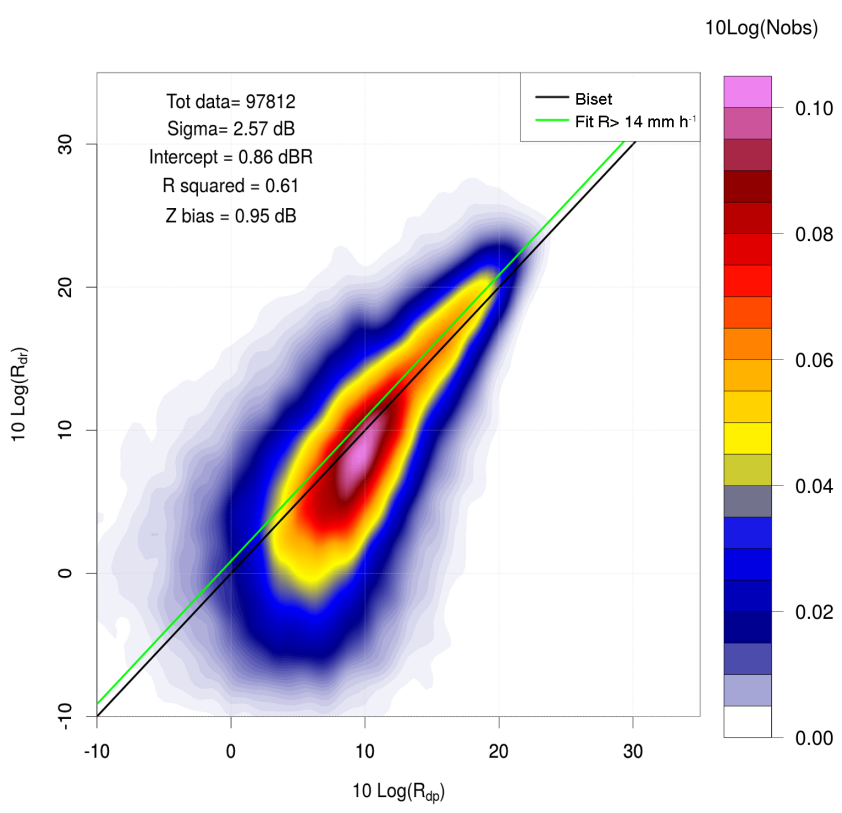

Figure 7. As in Fig. 6 but for the Monte Settepani radar.

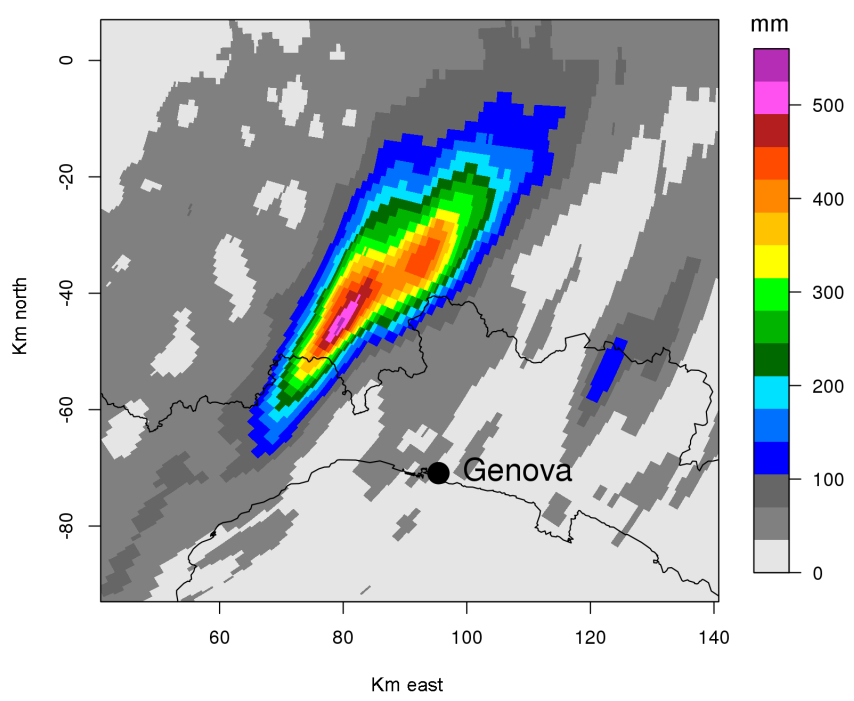

Figure 8. $24 \mathrm{~h}$ cumulative precipitation in millimeters (color scale) from the Bric della Croce radar on 13 October 2014. The axes display the east and north distances from the radar. The black point refers to the city of Genoa.

Fig. 10 shows the corresponding rain rate density plot. Due to the different geometric view of the storm, in this case the distribution of the observations in the polar domain is dominated by moderate rain rates, although for heavy rainfall the agreement is quite good, with a computed system gain of only $-0.13 \mathrm{~dB}$.

\subsection{Monitoring of the radar calibration stability}

Between the absolute calibration checks, the radar calibration is monitored by the ground clutter calibration and the Sun calibration. In addition, during precipitation, the intercalibration procedure is performed.

\subsubsection{Intercalibration}

Whenever precipitation is occurring on the overlapping area between the two radars, the intercalibration is performed as described in Sect. 3.2. The intercalibration results are displayed as

- a density scatterplot of all reflectivity data;

- a density scatterplot of reflectivity pairs, associated with $\rho_{h v}>0.95$, acquired below the melting layer and in dry-radome conditions.

For each density scatterplot, a linear fit is compared with a $1: 1$ slope. If the radar calibration degrades, the system bias appears as a nonzero intercept value of the fit. The amount of scatters may vary depending on several factors, including the temporal and spatial alignment of the observations and the type of the precipitation (stratiform vs. convective). In the figures, the total number of data, the residual standard error 


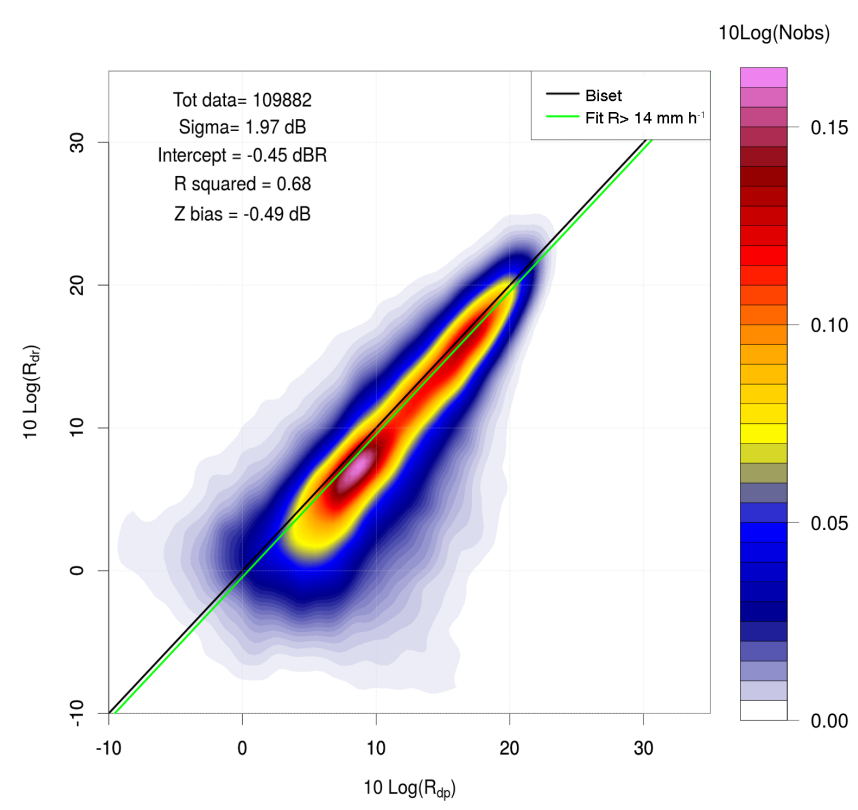

Figure 9. As in Fig. 6 but for the Bric della Croce radar, 13 October 2014.

of the fit (Sigma), the intercept value and the linear correlation coefficient $R$ are displayed. In Fig. 11, the intercalibration performed on 28 July 2014 is displayed. First, the intercalibration is executed without thresholds on the copolar correlation coefficient, including all reflectivity irrespective of the height relative to the freezing level. In Fig. 11 (left), the highest density of reflectivity pairs, denoted with warm colors, is located above the $1: 1$ line (black), and the total number of reflectivity pairs is about 56000 . A linear fit is applied on the reflectivity pairs with slope fixed at 1 , and the computed intercept is about $4 \mathrm{dBZ}$ with a fit uncertainty of about $6 \mathrm{~dB}$. Then, the reflectivity pairs are filtered according to the aforementioned selection criteria. In Fig. 11 (right), the highest density of reflectivity is closer to the $1: 1$ line, and the total number of data is about 4000 . Hence, the selection criteria have reduced the total number of reflectivity pairs by about an order of magnitude. The intercept is $2.4 \mathrm{dBZ}$, and the fit uncertainty has been reduced to about $4 \mathrm{~dB}$. Therefore, the intercept value is positive, meaning that the Monte Settepani radar overestimates the radar reflectivity values of rainfall when compared to the Bric della Croce radar.

\subsubsection{Ground clutter calibration}

The online hydrometeor classification processing allows selecting the polar volumes without meteorological echoes for application of the ground clutter calibration. The output of the daily calibration is the set of the individual ground clutter ECDFs, from which suitable visualizations may be implemented for ease of online monitoring. In the current implementation, the image of the daily ECDFs of horizontal

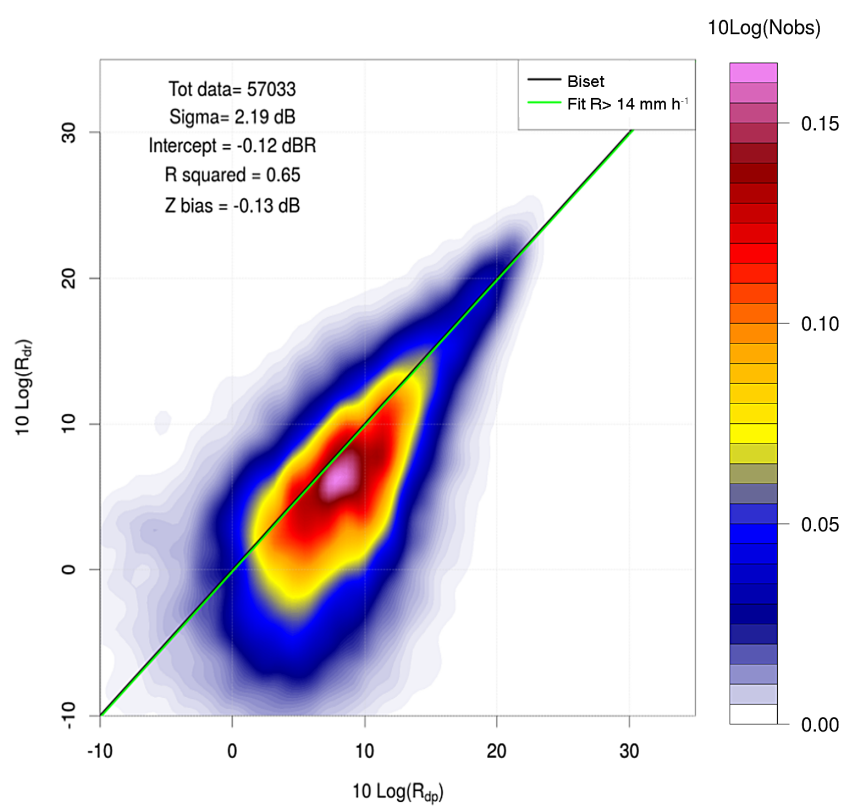

Figure 10. As in Fig. 6 but for the Monte Settepani radar, 13 October 2014 .

and vertical reflectivity with the enlargement around the 95th percentile are displayed. In addition, the historical trend of the daily average 95 th percentile is produced as a time series plot.

Figure 12 is an example of ground clutter calibration in normal operational conditions: the 95th-percentile values of $Z_{\mathrm{H}}$ and $Z_{\mathrm{V}}$ are very similar, and the spread of the individual ECDFs around the 95th percentile is quite narrow. When the enlargement around the 95th percentile is compared, the ECDFs of the horizontal polarization channel reach the 95th percentile at a value about $0.5 \mathrm{~dB}$ lower than the vertical polarization channel. The historical trend from 28 July to 13 October 2014 shows a remarkable stability of the radar calibration (Fig. 13). The variability of the difference between to two channels is also quite limited over the study period and always within the standard deviation of the daily sample. It is interesting to note the increase of the 95th percentile around 27 September 2014: analyzing the meteorological conditions and using radio sounding data, we noticed that the radar beam was likely bent, due to anomalous propagation. Thus, in this case, the anomalous propagation of the radar beam added about $1 \mathrm{~dB}$ to the trend value of the 95thpercentile mean.

\subsubsection{Sun calibration}

Every 5 days, the radar calibration is operatively monitored by the Sun calibration performed on the previous 5 days. The daily number of detected solar interferences depends on the season, i.e., on the ascent/descent rate of the Sun, on the solar activity, on scanning strategy and on the sensitivity of 

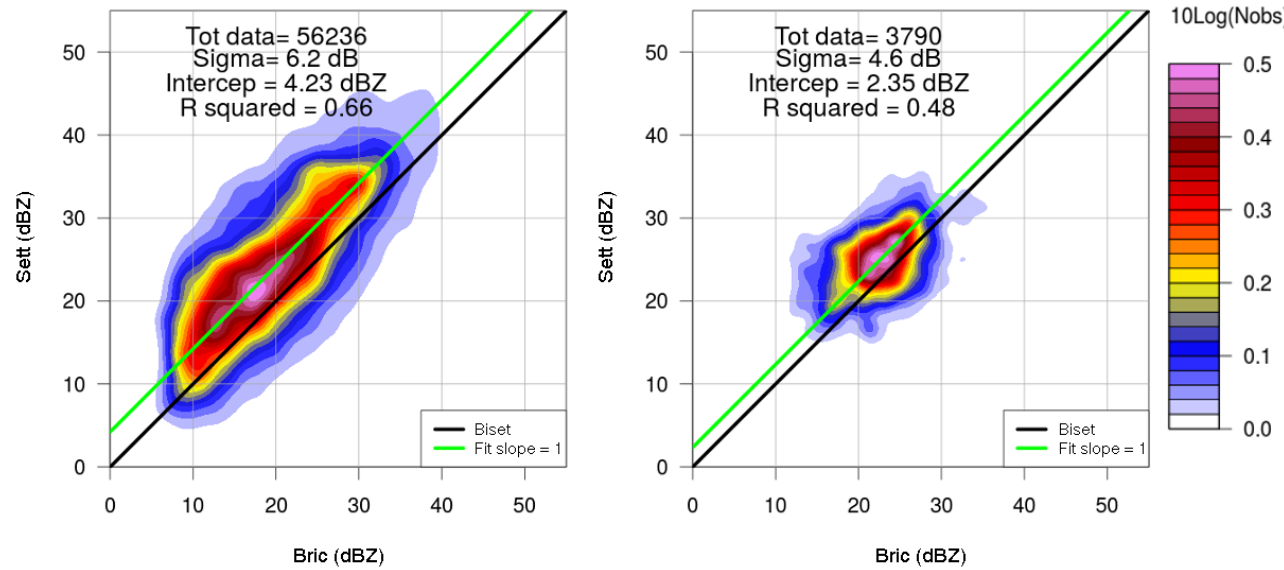

Figure 11. Intercalibration between Bric della Croce and Monte Settepani, 28 July 2014. Comparison considering all the reflectivity pairs (left) and the reflectivity pairs, associated with $\rho_{h v}>0.95$, acquired during dry-radome conditions and below the melting layer (right). The color bar displays the number of observations in logarithmic units using $0.25 \mathrm{dBZ}$ intervals for both axes.

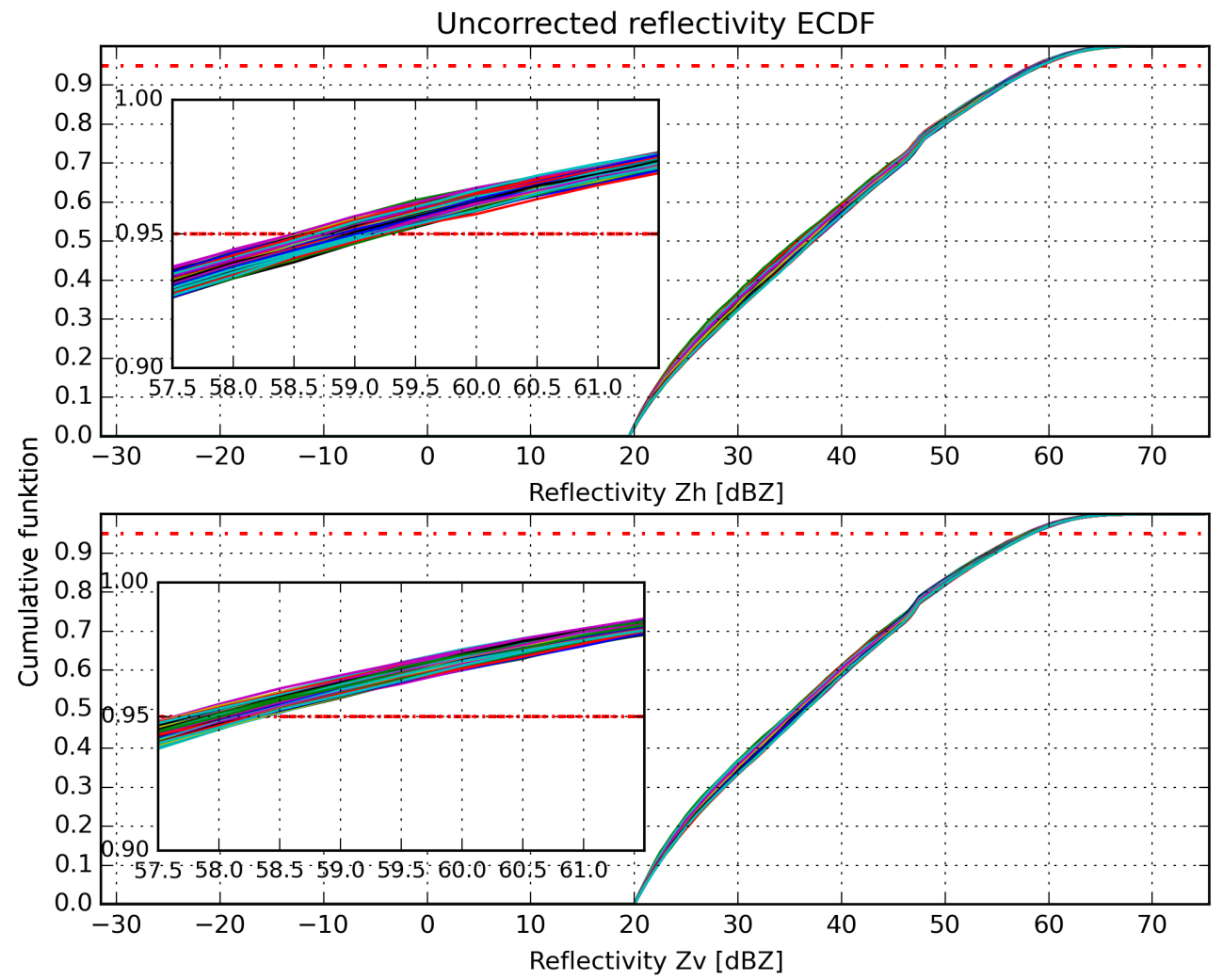

Figure 12. $Z_{\mathrm{H}}$ and $Z_{\mathrm{v}}$ ECDF with respective enlargements around the 95th percentile, Bric della Croce radar at elevation $0.5^{\circ}, 7$ October 2014. Each line represents the ECDF for a single plan position indicator (PPI).

the radar receiver. This procedure has been applied to both radars, but in this section only the results for the Monte Settepani one are discussed.

During September 2014, the Monte Settepani radar collected 130 solar interferences, represented in the scatterplot of Fig. 14. The $x$ axis represents the $\Delta$ azimuth (see
Sect. 3.4), the $y$ axis the $\Delta$ elevation and the colors the received power in decibel milliwatts $(\mathrm{dBm})$. The isolines show the value of the received power at a given point on the $\Delta$ azimuth- $\Delta$ elevation plane, computed by the theoretical model fit. It is evident that the solar interferences are scattered over roughly $1^{\circ}$ in both azimuth and elevation around 

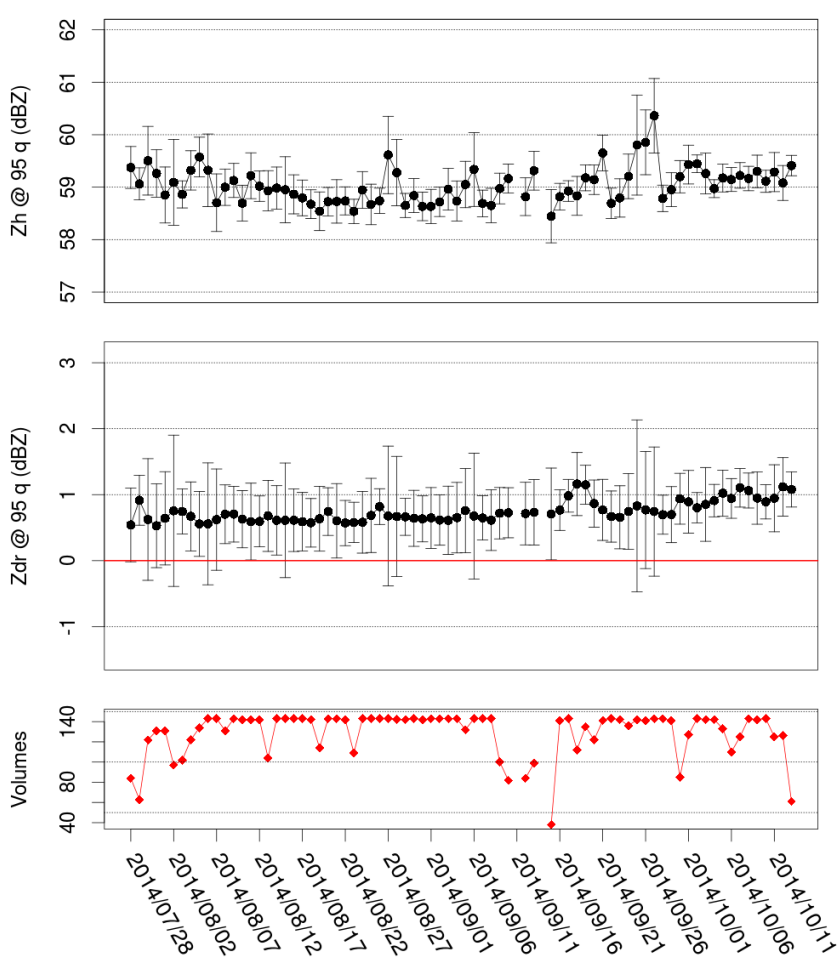

Figure 13. Daily mean values of the 95 th percentile of all daily scans of $Z_{\mathrm{H}}$ (top) and $Z_{\mathrm{dr}}$ (center) ECDFs. The bottom plot shows the number of scans used to compute the daily mean values. The error bars represents the standard deviation.

the antenna pointing, the black rhombus in Fig. 14. The calculated bias in azimuth and elevation, the mean squared error and the $Z_{\mathrm{dr}}$ bias are reported in the figure.

The solar interferences are also analyzed to evaluate the receiver calibration, in addition to the antenna pointing accuracy during the study period. The computed power at the top of the atmosphere $\left(P_{\mathrm{TOA}}\right)$ is shown together with the reference values form DRAO in Fig. 15. The computed value of the power at the top of the atmosphere seen by the radar from the daily solar interferences is displayed with the fit uncertainty. The $P_{\mathrm{TOA}}$ values have been chosen as the quantity to be compared with the DRAO reference since it is calculated by the theoretical model and represents the solar power received by the radar when the antenna beam is centered on the Sun. The reference values are considered without uncertainty. The numbers above the $x$ axis represent the number of interferences on which the mean and uncertainty values are calculated. The days with missing values are due to a radar hardware failure. The mean difference between the daily $P_{\mathrm{TOA}}$ value and the DRAO reference is $0.5 \mathrm{dBm}$, and the correlation is 0.88 . The azimuthal and elevation biases are computed by the three parameters' model inversion (Altube et al., 2015). The azimuth bias and elevation bias from July to October 2014 are displayed in Fig. 16. The azimuth and elevation biases are both slightly negative but approxi-

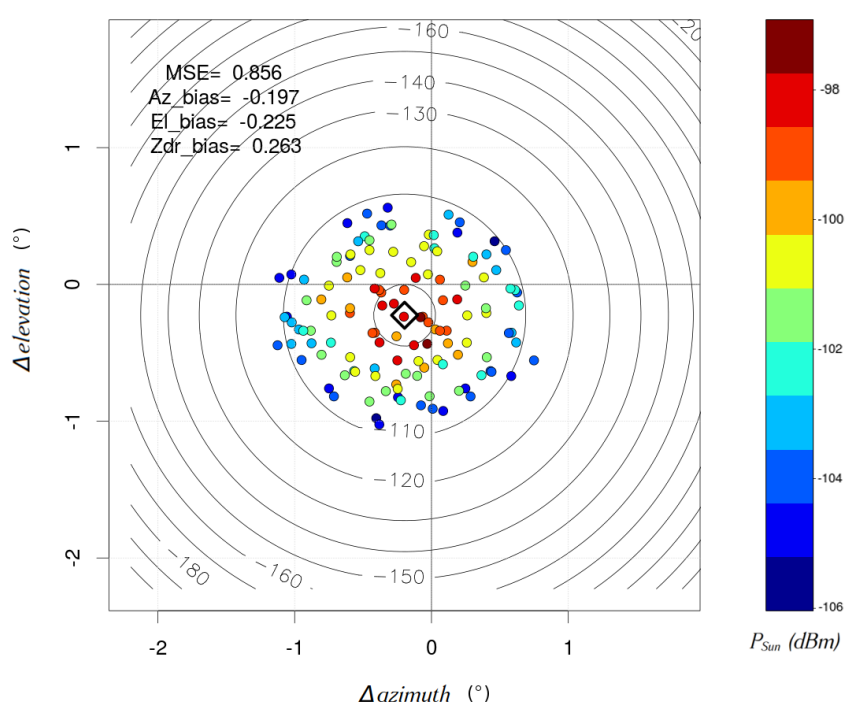

Figure 14. Scatterplot of solar interferences collected by the Monte Settepani radar during September 2014. The $x$ axis represents the difference between the radar and Sun azimuths, the $y$ axis the difference between the radar and Sun elevations, and the colors the received power in decibel milliwatts $(\mathrm{dBm})$. The isolines show the value of the received power in a given point on the $\Delta$ azimuth$\Delta$ elevation plane, computed by the theoretical model fit. The black rhombus is the antenna pointing. The calculated bias in azimuth and elevation, the mean squared error and the $Z_{\mathrm{dr}}$ bias are reported in the figure.

mately constant during the whole period. The Sun calibration also allows the values of the differential reflectivity to be monitored. As previously mentioned, the intrinsic solar $Z_{\mathrm{dr}}$ should be 0 since the Sun is an unpolarized source of microwave radiation. In this work, the observed solar $Z_{\mathrm{dr}}$ is monitored considering its mean value along the solar ray. The daily value of the observed solar $Z_{\mathrm{dr}}$ is shown in Fig. 17, where the error bars represent the standard deviation calculated on the data of the given day. The mean value of the daily $Z_{\mathrm{dr}}$ values deviates significantly from the expected $0 \mathrm{~dB}$ value, but no remarkable changes are visible during the study period.

\section{Discussion and conclusions}

Four different procedures have been considered to operationally monitor the radar calibration, namely selfconsistency, ground clutter calibration, intercalibration and Sun calibration. The proposed approach for online monitoring consists in the integration of the results of the discussed calibration techniques. The study period has been chosen as 28 July-13 October 2014, and the measurements have been acquired by the radars managed by Arpa Piemonte, Bric della Croce and Monte Settepani located in NW Italy, considering the operational volume scans with 10 min update frequency. 


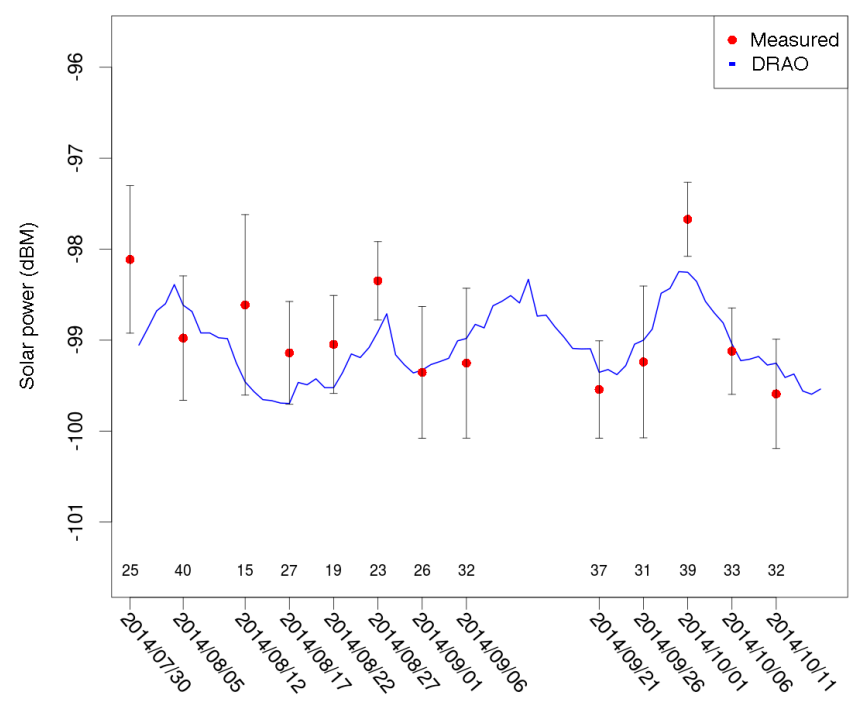

Figure 15. Daily analysis of the solar interferences detected by the Monte Settepani radar during July-October 2014. The value of the power at the top of the atmosphere $\left(P_{\mathrm{TOA}}\right)$ seen by the radar, computed from the daily solar interferences, is displayed as red points. The error bars are calculated, for each day, as the square root of the differences between all the measured solar powers and the corresponding values computed by the theoretical model. The blue points display the DRAO reference values of the solar power. The amount of the collected solar interferences for each day is shown by the numbers in the plot.

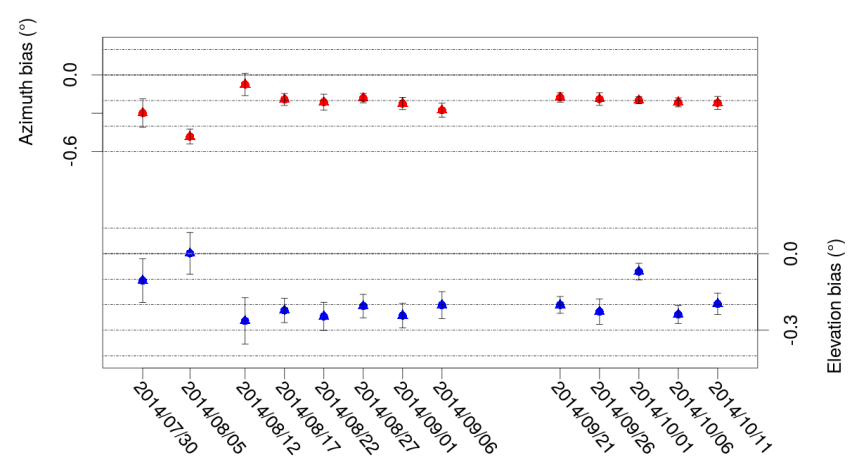

Figure 16. Daily analysis of azimuth bias (top) and elevation bias (bottom) of the Monte Settepani radar during July-October 2014.

The reference absolute calibration is provided by the selfconsistency technique, requiring that $Z_{\mathrm{dr}}$ is properly calibrated, which is verified in drizzle medium. Nevertheless, since the operative scan cannot be modified to introduce the vertical pointing and since the accuracy of the $Z_{\mathrm{dr}}$ calibration in drizzle is about $0.5 \mathrm{~dB}$, the stability of the $Z_{\mathrm{dr}}$ calibration is monitored using the Sun returns, which shows a higher accuracy. The self-consistency technique is influenced by the adopted drop shape model and variability of the DSD: in particular, different DSDs and drop shape models can produce up to a $3-4 \mathrm{~dB}$ difference in the reflectivity estimates

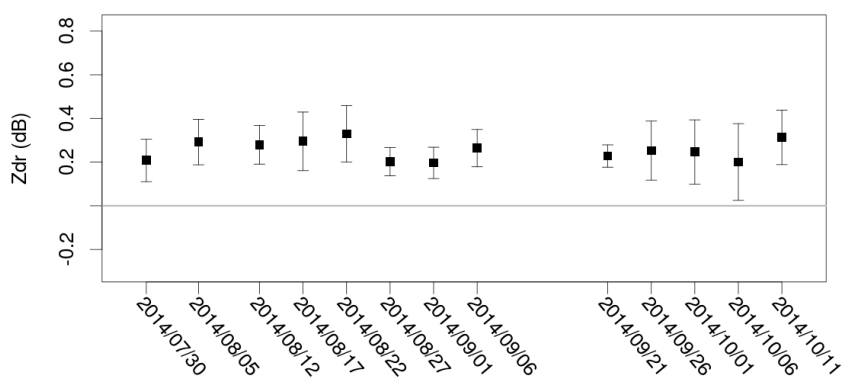

Figure 17. Daily analysis of the differential reflectivity of the solar interferences detected by the Monte Settepani radar during JulyOctober 2014. The error bars represent the standard deviation of the daily $Z_{\mathrm{dr}}$ values.

(Ryzhkov et al., 2005). The proposed approach considers observations collected over a whole day, disregarding weak rainfall intensity data, where $K_{\mathrm{dp}}$ is excessively affected by noise.

Figure 18 provides a comprehensive view of the results achieved using the calibration monitoring techniques. This combined visualization represents an effective tool to operationally monitor and detect eventual drifts in the radar calibration, allowing a quick and efficient interpretation of the results obtained with the individual techniques.

For the Bric della Croce radar, using the self-consistency, a system bias of less than $1 \mathrm{~dB}$ has been found during the selected rainfall events, except for 15 August 2014, when the system gain bias reaches $1.2 \mathrm{~dB}$.

The ground clutter and Sun calibration of the Bric della Croce radar (Fig. 18, second panel) show a good stability of the radar calibration.

For the Monte Settepani radar, the self-consistency calibration allowed a system gain bias of $1 \mathrm{~dB}$ (28 July 2014) and of $-0.1 \mathrm{~dB}$ (13 October 2014) to be estimated. The step of about $3 \mathrm{~dB}$ between 4 August and 13 August, and of about $4 \mathrm{~dB}$ between 23 August and 18 September, is noticeable, indicating a calibration issue. The self-consistency, the intercalibration and the Monte Settepani ground clutter calibration (Fig. 18, top third and bottom panels) suggest that the study period may be divided into three sections: from 28 July to 12 August, from 12 August to 17 September and from 17 September to 13 October. Until 12 August, the mean value of the Monte Settepani ground clutter 95th percentile is $57 \mathrm{~dB}$, and during rainfalls the Monte Settepani radar overestimates the radar reflectivity of about $2 \mathrm{~dB}$ when compared to the Bric della Croce radar. On 12 August, a transmitter module broke down and the radar continued the normal operations with a lower pulse power, due to a decrease of the Klystron cathode current. In fact, the ground clutter calibration shows a step between 11 and 12 August, and the 95th percentile of the reflectivity ECDF decreases at $54.7 \mathrm{~dB}$. In the same period the intercalibration shows the Monte Settepani underestimation of the radar reflectivity. On 4 September a second 

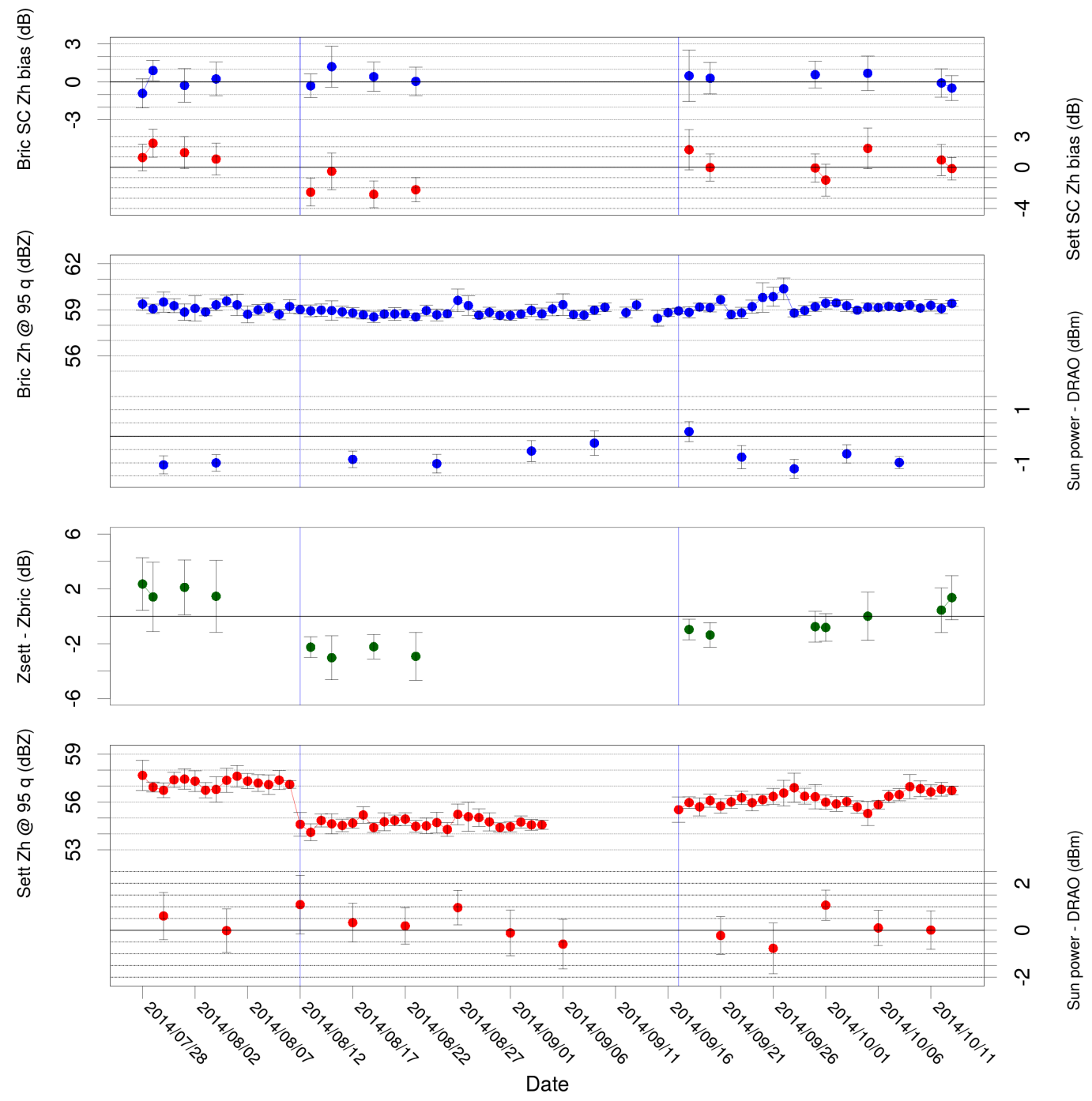

Figure 18. Monitoring the stability of radar calibration. From the top, Bric della Croce (blue) and Monte Settepani (red) self-consistency; Bric della Croce ground clutter and Sun calibrations; Bric della Croce and Monte Settepani intercalibration (green); Monte Settepani ground clutter and Sun calibrations. The error bars represent the estimated uncertainty. In the Sun calibration, the DRAO reference at 20:00 UTC, as reported in Wolff et al. (2015), is subtracted from the observed solar power. The vertical blue lines divide the study period in three sectors as reported in the text.

module broke down and the radar stopped. The radar was repaired on 17 September, when two transmitter modules were substituted. Nevertheless, the ground clutter calibration from 17 September to 13 October displays a mean value of $56 \mathrm{~dB}$, $1 \mathrm{~dB}$ lower than the mean value until 12 August. This difference is also pointed out by the self-consistency as a decrease of about $1 \mathrm{~dB}$ in the system gain bias between 28 July and 13 October. On the other hand, the receiving-chain Sun calibration results show a fair agreement between the solar power at the top of the atmosphere as seen by the radar and the DRAO reference.

The decrease of the Monte Settepani system bias is $1.1 \mathrm{~dB}$. Even if this value is lower than the self-consistency accuracy, this change is also found in the ground clutter calibration from the difference between the mean value of the 95th percentile of clutter echo reflectivity averaged before 12 August and after 17 September. The integrated calibration approach then suggests that this change in the absolute calibration of the radar should not be ascribed to the self-consistency uncertainty but may likely be related to some change in the transmitter subsystem during the corrective maintenance on 17 September.

We can note that the self-consistency trends of the Bric della Croce and Monte Settepani radars are similar, indicating a correlation in the estimates obtained using two independent sets of measurements acquired by two different systems. In fact, the standard deviation of the difference of the self-consistency biases between the Monte Settepani and 


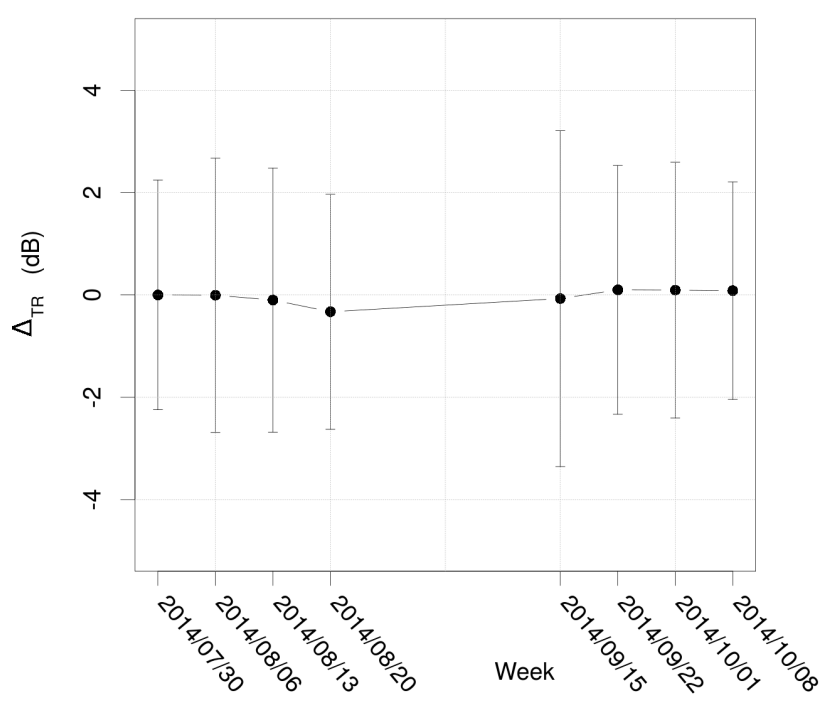

Figure 19. $\Delta_{\mathrm{TR}}$, as defined in Sect. 3, computed weekly during the study period for the Bric della Croce radar. The error bars represent its uncertainty.

Bric della Croce radars $(0.82 \mathrm{~dB})$ is lower than the quadratic sum of the two separate standard deviations, computed on the two radars separately $(1.12 \mathrm{~dB})$. This seems to indicate a likely role of the specific meteorological conditions and associated precipitation microphysics (Ryzhkov et al., 2005).

A more comprehensive monitoring tool, $\Delta_{\mathrm{TR}}$, incorporating the clutter and the self-consistency calibration, is reported in Figs. 19 and 20, showing a mean value around 0 for the Bric della Croce radar and pointing out the calibration issue in the Monte Settepani radar. In fact, the decrease of the $\Delta_{\mathrm{TR}}$ from 0 to $-2.5 \mathrm{~dB}$ is remarkable. The root mean squared error (RMSE) of the transmission and reception calibration is evaluated for the Bric della Croce radar, since no calibration issues were found. The RMSE is $0.38 \mathrm{~dB}$ for the integrated approach; when considering the techniques separately, the clutter calibration RMSE is $0.45 \mathrm{~dB}$ and self-consistency RMSE is $0.79 \mathrm{~dB}$. The integration of the techniques, which monitor the transmission and reception calibration, provides a more robust and stable tool with which to detect eventual drifts in the radar calibration.

The impact of a proper calibration is investigated in the QPE product. In Fig. 21, we show the comparison between the retrieved rain rate from radar measurements and the rain rate measured by rain gauges located within $70 \mathrm{~km}$ from the Monte Settepani radar. The radar-based rainfall estimation is obtained using a $Z-R$ relation with coefficients $A=300$ and $B=1.5$ (Joss and Waldvogel, 1970). The left-side scatterplot displays the rainfall that occurred during 28 and 29 July, and 1 and 4 August. This scatterplot is considered as a reference since no calibration issues were found on those days. Instead, the right-side scatterplot shows, in blue color, the rain rate comparison during 13, 15, 19 and 23 August,

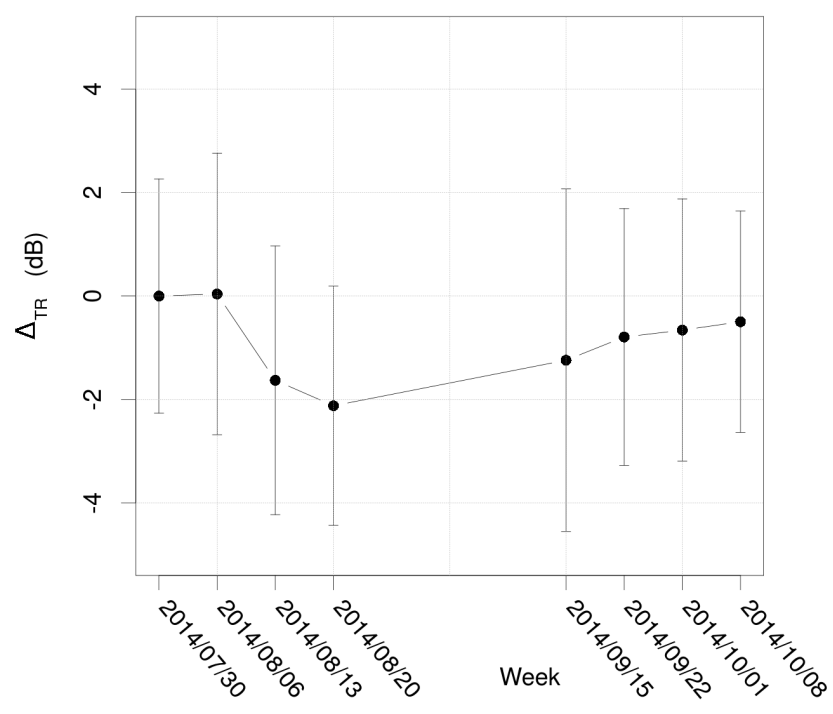

Figure 20. As in Fig. 19 but for the Monte Settepani radar.

when the self-consistency and clutter calibration techniques show a radar miscalibration (about $3 \mathrm{~dB}$ ). After correction of the radar reflectivity according to the values found by the aforementioned procedures (red color in the scatterplot), the magnitude of the normalized mean bias is substantially decreased.

Each calibration procedure is able to monitor a specific part of the radar system (e.g., receiving chain, transmitting chain, antenna pointing, polarization channels), and the selfconsistency technique allows the absolute calibration of the radar to be estimated. The advantages of this integrated approach are (1) the extensive use of operational routines that do not require stopping the radar and (2) the integration of the results of several techniques exploiting different targets (ground clutter, Sun, rainfall) and based on different measurements (reflectivity only, polarimetric observations). The self-consistency procedure has been applied, in this preliminary work, on the precipitation cases selected for the intercalibration technique. In order to increase the accuracy of the procedure, more work is needed in particular to derive robust automatic data selection criteria. The potential limitations of the proposed method could be related to the winter months, when echoes in the lowest atmospheric levels are from solid precipitation. The self-consistency and the intercalibration approach, which are intended for use in the liquid phase, cannot be performed. In addition, since winter is the driest period in the considered region, the clutter and Sun calibrations become especially relevant during this part of the year.

Overall, the integrated approach showed a capability to detect calibration losses with a high level of confidence derived from the combination of different techniques, and with an accuracy of about $2 \mathrm{~dB}$. Although a $1 \mathrm{~dB}$ calibration accuracy is in general the ultimate goal, the achieved results exploiting 

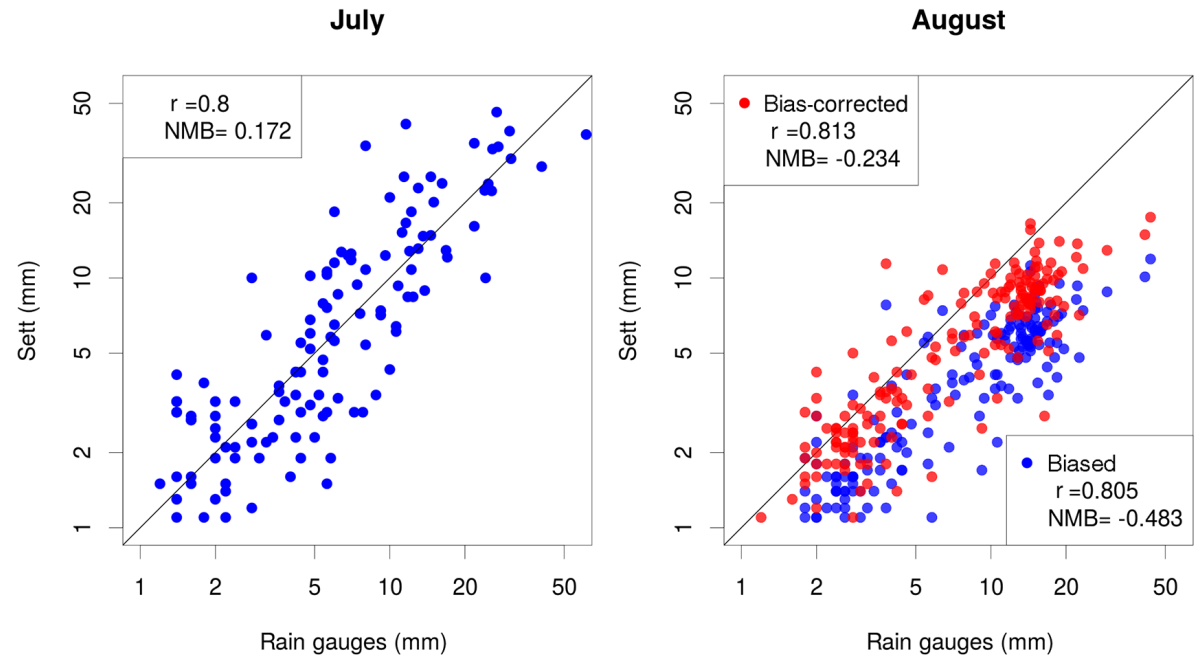

Figure 21. Comparison between rain rates retrieved from radar measurements and rain rates measured by rain gauges within $70 \mathrm{~km}$ from the Monte Settepani radar. The left panel is assumed as a reference since there was no evidence of calibration issues. In the right panel, the blue points refer to rain rates retrieved when the Monte Settepani radar suffered from miscalibration. The radar measurements are corrected according to the integrated-approach result, and the estimated rain rates are shown in red. The correlation coefficient, $r$, and the normalized mean bias, NMB, are reported.

only the operational radar scans are considered adequate to automatically detect any unexpected change in the radar system requiring further data analysis or on-site measurements.

\section{Data availability}

The radar data used in this study are available by request from Arpa Piemonte (www.arpa.piemonte.it).

Acknowledgements. The work has been in part supported by a grant, D.D. no. 1243 of 20 December 2013, by the Italian National Civil Protection. The participation of V. Chandrasekar was supported by the DOE-ASR program.

Edited by: G. Vulpiani

Reviewed by: four anonymous referees

\section{References}

Altube, P., Bech, J., Argemi, P., Rigo, T., and Pineda, N.: Weather radar online Sun-monitoring in presence of leverage outliers: five or three parameter model inversion?, in: ERAD 2014 - The eighth European conference on radar in meteorology and hydrology, 2014.

Altube, P., Bech, J., Argemí, O., and Rigo, T.: Quality control of antenna alignment and receiver calibration using the Sun: adaptation to mid range weather radar observations at low elevation angles, J. Atmos. Ocean. Tech., 927-942, 2015.

Beard, K. and Chuang, C.: A New Model for the Equilibrium Shape of Raindrops, J. Atmos. Sci., p. 16, 1987.
Bechini, R. and Chandrasekar, V.: A Semisupervised Robust Hydrometeor Classification Method for Dual-Polarization Radar Applications, J. Atmos. Ocean. Tech., 32, 22-47, 2015.

Bringi, V. N. and Chandrasekar, V.: Polarimetric Doppler Weather Radar, principles and applications, Cambridge University Press, 2001.

Bringi, V. N., Chandrasekar, V., Balakrishnan, N., and Zrnic, D. S.: An Examination of Propagation Effects in Rainfall on Radar Measurements at Microwave Frequencies, J. Atmos. Ocean. Tech., 7, 829-840, 1990.

Gabella, M., Sartori, M., Boscacci, M., and Germann, U.: Vertical and Horizontal Polarization Observations of Slowly Varying Solar Emissions from Operational Swiss Weather Radars, Atmosphere, 6, 50-59, 2014.

Gorgucci, E., Scarchilli, G., and Chandrasekar, V.: Calibration of radars using polarimetric techniques, IEEE T. Geosci. Remote, 30, 853-858, 1992.

Gorgucci, E., Scarchilli, G., Chandrasekar, V., and Bringi, V.: Rainfall estimation from polarimetric radar measurements: Composite algorithms immune to variability in raindrop shape-size relation, J. Atmos. Ocean. Tech., 18, 1773-1786, 2001.

Holleman, I. and Beekhuis, H.: Weather radar monitoring using the sun, Tech. rep., KNMI Koninklijk Nederlands Meteorologisch Instituut, De Bilt, technical report: TR-272, KNMIAUT2004, ISBN: 9036922615 ISSN: 01691708, 2004.

Holleman, I., Huuskonen, I., A., Kurri, M., and Beekhuis, H.: Operational Monitoring of Weather Radar Receiving Chain Using the Sun, J. Atmos. Ocean. Tech., 27, 159-166, 2010a.

Holleman, I., Huuskonen, A., Gill, R., and Tabary, P.: Operational monitoring of radar differential reflectivity using the sun, J. Atmos. Ocean. Tech., 27, 881-887, 2010 b.

Huuskonen, A. and Holleman, I.: Determining weather radar antenna pointing using signals detected from the sun at low antenna elevations, J. Atmos. Ocean. Tech., 24, 476-483, 2007. 
Huuskonen, A., Kurri, M., Hohti, H., Beekhuis, H., Leijnse, H., and Holleman, I.: Radar performance monitoring using the angular width of the solar image, J. Atmos. Ocean. Tech., 31, 1704-1712, 2014.

Joss, J. and Waldvogel, A.: A method to improve the accuracy of radar measured amounts of precipitation, in: 14th Conference on radar meteorology (preprints), 237-238, 1970.

Météo France and Emilia Romagna: Evaluation of New Radar Technologies, http://www.eumetnet.eu/opera (last access: 1 November 2016), 2012.

OPERA 3-WP1.4b: Project E-NradTech "Evaluation of New Radar Technologies" Subproject 1: Operational monitoring and use of polarimetric $\mathrm{C}$ and S-band radars, http://www.eumetnet.eu/sites/default/files/OPERA_2012_ 03_Operational_polarimetry_in_C_and_S_bands.pdf, 2012.

Ribaud, J.-F., Bousquet, O., Coquillat, S., Al-Sakka, H., Lambert, D., Ducrocq, V., and Fontaine, E.: Evaluation and application of hydrometeor classification algorithm outputs inferred from multi-frequency dual-polarimetric radar observations collected during HyMeX, Q. J. Roy. Meteor. Soc., 142, 95-107, doi:10.1002/qj.2589, 2015.

Rinehart, R. E.: Radar for Meteorologists, Rinehart Publications, 4 edn., 2004.

Ryzhkov, A. V., Giangrande, S. E., Melnikov, V. M., and Schuur, T. J.: Calibration issues of dual-polarization radar measurements, J. Atmos. Ocean. Tech., 22, 1138-1155, 2005.

Scarchilli, G., Gorgucci, E., Chandrasekar, V., and Dobaie, A.: Selfconsistency of polarization diversity measurement of rainfall, IEEE T. Geosci. Remote Sens., 34, 22-26, 1996.
Silberstein, D., Wolff, D., Marks, D., Atlas, D., and Pippit, J.: Ground Clutter as a Monitor of Radar Stability at Kwajalein, RMI, J. Atmos. Ocean. Tech., 25, 2037-2045, 2008.

Tapping, K.: Antenna calibration using the $10.7 \mathrm{~cm}$ solar flux, in: Workshop on Radar Calibration, Albuquerque, NM, 2001a.

Tapping, K.: Antenna Calibration Using the $10.7 \mathrm{~cm}$ Solar Flux, in: Workshop on Radar Calibration, Abuquerque, AMS, $2001 \mathrm{~b}$.

Testud, J., Bouar, E. L., Obligis, E., and Ali-Mehenni, M.: The rain profiling algorithm applied to polarimetric weather radar, J. Atmos. Ocean. Tech., 17, 332-356, 2000.

Ulbrich, C. W.: Natural variations in the analytical form of the raindrop size distribution, J. Clim. Appl. Meteorol., 22, 1764-1775, 1983.

Vukovic, Z., Young, J. M., and Donaldson, N.: Inter-radar comparison accounting for partially overlapping volumes, ERAD, 2014.

Wang, Y. and Chandrasekar, V.: Algorithm for estimation of the specific differential phase, J. Atmos. Ocean. Technol., 26, 25652578, 2009.

Whiton, R. C., Smith, P. L., and Harbuck, A. C.: Calibration of weather radar systems using the sun as a radio source, in: 17th Conference on Radar Meteorology, 60-65, 1976.

Wolff, D. B., Marks, D. A., and Petersen, W. A.: General Application of the Relative Calibration Adjustment (RCA) Technique for Monitoring and Correcting Radar Reflectivity Calibration, J. Atmos. Ocean. Tech., 32, 496-506, 2015. 